\title{
The Impact of Dual Apprenticeship Programmes on Early Labour Market Outcomes: A Dynamic Approach*
}

\author{
By Brecht Neyt, ${ }^{\text {i }}$ Dieter Verhaest, ${ }^{\text {ii }}$ and Stijn Baert ${ }^{i i i}$
}

Published in Economics of Education Review

\begin{abstract}
This study examines the impact of enrolling into dual apprenticeship programmes during secondary education on six early employment outcomes. Our contribution to the literature is threefold. First, we apply a method that has rarely been used in this literature to control for potential selection biases. Second, this method allows us to distinguish between the programmes' direct effect (conditional on educational achievement) and indirect effect (via educational achievement) on labour market outcomes. Third, we examine the impact of two distinct dual apprenticeship programmes in a novel setting: Flanders (Belgium). We find evidence for short-term labour market advantages only for the programme with the most days of on-the-job training, which fade out quickly over time.
\end{abstract}

Keywords: vocational education; transitions in youth; dynamic selection; education; labour.

JEL-codes: I21; I26; J21.

Citation: Neyt, B., Verhaest, D., \& Baert, S. (2020). The impact of dual apprenticeship programmes on early labour market outcomes: A dynamic approach. Economics of Education Review, 78, 102022.

https://doi.org/10.1016/j.econedurev.2020.102022

\footnotetext{
* Acknowledgements: We thank the participants of the 2018 LEER conference, 2018 IAAE conference, and 2018 EEA conference for their insightful suggestions. Additionally, we thank two anonymous referees and one co-edito for their constructive comments. This research did not receive any specific grant from funding agencies in the public, commercial, or not-for-profit sectors. Declarations of interest: none.

' Corresponding author. Ghent University, Sint-Pietersplein 6, 9000 Ghent, Belgium; Brecht.Neyt@UGent.be; +32499164992.

ii KU Leuven, Ghent University, and GLO.

iii Ghent University, Research Foundation - Flanders, University of Antwerp, Université catholique de Louvain, IZA, GLO, and IMISCOE.
} 


\section{Introduction}

Over the past decade, youth unemployment rates in the European Union greatly exceeded the unemployment rates of non-youths, as indicated in Figure $1 .{ }^{1}$ This is a fortiori the case in Belgium, which is the country from which our data samples were taken. Additionally, unemployment rates are higher for youths who enter the labour market without a higher education degree, as can be seen in Figure 2. The phenomena in Figure 1 and Figure 2 indicate a rather poor transition from secondary education to the regular labour market. Therefore not surprisingly, smoothing this transition is a key ambition of many education systems (van de Werfhorst, 2014)

\section{< Figure 1 about here >}

\section{< Figure 2 about here >}

One potential way of pursuing this is by more closely linking secondary education to the labour market, for example by encouraging students to enrol in dual apprenticeship and other vocational education programmes (Ryan, 2001; Zimmerman et al., 2013). By completing vocational education and, in particular, participating in on-the-job learning through apprenticeship training, students gain ready-to-use skills that immediately increase their employability when they enter the labour market (Shavit \& Müller, 2000; Hanushek, Schwerdt, Woessman, \& Zhang, 2017). Moreover, apprenticeships may provide immediate access to jobs if employers use them as a screening device (Wolter \& Ryan, 2011).

\footnotetext{
${ }^{1}$ The youth unemployment rate is calculated as the ratio between the unemployed in the age group of 15 to 24 years old and the total labour force (employed and unemployed, i.e. youths in education excluded) for that age group. The non-youth unemployment rate is calculated as the ratio between the unemployed in the age group 25 to 74 years old and the total labour force (employed and unemployed) for that age group.
} 
But for three main reasons, this advantage when entering the labour market might decrease (and even turn into a disadvantage) over time. First, the occupation-specific skills acquired in vocational education may quickly become obsolete ('external depreciation of human capital'; Weber, 2014). This might be especially true today with automation and digitalisation leading to rapid technological change (Krueger \& Kumar, 2004; Hampf \& Woessmann, 2017). Second, occupation-specific skills are sensitive to changes in labour demand, so that their premiums might not be robust to these changes (Golsteyn \& Stenberg, 2017). Third, vocational education comes at the cost of less general education, the latter which focuses more on cognitive skills, problem solving, and critical thinking. Less development of these skills is expected to decrease students' potential for lifelong learning and learning on the job, so that students in vocational education are expected to be less capable of adapting to changing labour market conditions and, therefore, are less employable in the long run (Weber, 2014; Hanushek et al., 2017). Indeed, Brunello (2003) suggested that individuals who followed more general education invest more in training after formal education. Additionally, Rosenbaum (2003) argued that many employers are looking for individuals with a high capacity for learning on the job instead of for individuals with a given set of skills because in many jobs competences must be acquired on the job.

Multiple studies have found empirical evidence for this trade-off between short-term advantages and long-term disadvantages of vocational education on the labour market. We discuss them in the next section. The present study adds to this existing literature in three main ways. First, we are one of the first in this literature to apply a dynamic discrete choice model to estimate the impact of dual apprenticeship programmes on labour market outcomes at different stages in the early career. With this model we aim to control for both self-selection into dual apprenticeship programmes based on unobservable characteristics 
and for the dynamic selection that takes place in the educational career. Both potential selection effects are discussed in detail in the next section, together with a discussion of how methods used in earlier studies tried to control for these two potential selection effects. Additionally, we indicate how our methodological approach allows us to contribute to these earlier studies.

Second, our model also allows us to make a distinction between the total, direct, and indirect effects of dual apprenticeship programmes on labour market outcomes. The direct effect can be considered as the 'pure' effect of enrolment in dual apprenticeship programmes on labour market outcomes, i.e. the effect driven by the knowledge, skills, and social network acquired by being enrolled in dual apprenticeship programmes. The indirect effect stems from the effect that enrolment in dual apprenticeship programmes may have on further schooling outcomes, which in turn impact labour market outcomes. Naturally, the total effect is the sum of the direct and indirect effect and therefore captures both the effect of dual apprenticeship programmes conditional on potentially altered schooling outcomes (the direct effect) and the effect of dual apprenticeship programmes through potentially altered schooling outcomes (the indirect effect). We are convinced that the distinction between the total, direct, and indirect effects of dual apprenticeship programmes is an important one given the potential impact of these programmes on educational attainment. On the one hand, the practical focus in vocational programmes has been suggested in multiple studies to motivate certain students who would otherwise have dropped out of school to obtain a secondary education qualification (Bishop \& Mane, 2004; Plank, DeLuca, \& Estaction, 2008; Dougherty, 2018). On the other hand, students with school fatigue may realise through onthe-job experience that they want to go the labour market, which decreases their chances of obtaining a secondary education qualification. 
Third, we examine the impact of dual apprenticeship programmes in a region which has not been examined before with respect to this topic: Flanders - the northern, Dutch-speaking region of Belgium. An interesting feature of the education system in Flanders is that it organises two types of dual apprenticeship programmes. As the two programmes differ in the amount of on-the-job learning and in the role employers play in the organisation and design of the programme, our study is able to contribute to the discussion on the optimal design of vocational education programmes in general and dual apprenticeship programmes in particular by comparing the impact of the two dual apprenticeship programmes. Such comparison - which has been done in only few earlier studies - is substantially more meaningful than comparisons between different vocational education programmes conducted in most earlier studies, which compared the impact of vocational education programmes by comparing countries with differently organised education systems (Forster et al., 2016; Hampf \& Woessmann, 2017; Hanushek et al., 2017; Verhaest et al., 2018). Indeed, in such comparisons it cannot be ruled out that the apparent effect attributed to a certain vocational education programme is driven by other forms of heterogeneity between different education systems. ${ }^{2}$

The remainder of this study is organised as follows. In Section 2, we discuss the existing literature on the impact of vocational education on labour market outcomes. Section 3 sketches the education system in Flanders. Next, in Section 4 and Section 5, we discuss, respectively, the data and econometric model used to estimate the relationship between dual

\footnotetext{
2 One other study indirectly evaluated the labour market effects of alternative types of apprenticeship programmes. By evaluating a reform of the Italian apprenticeship system, Albanese, Cappellari, and Leonardi (2017) recently concluded that bringing the system closer to the German system - mainly by increasing the importance of on-the-job training - improved employment chances and wages in the first few years after the expiration of the apprenticeship contract. However, in contrast to our study, they did not test whether this new apprenticeship programme fares better than other, non-apprenticeship programmes.
} 
apprenticeship programmes and early labour market outcomes. In Section 6, the results of our analyses are presented and Section 7 concludes by formulating policy recommendations and suggestions for future research.

\section{Literature review}

As mentioned in the previous section, several recent studies found that the effect of vocational education (in comparison to more general education) on the probability of finding a job is initially positive, but declines over time (Korpi, de Graaf, Hendrickx, \& Layte, 2003; Parey, 2016; Brunello \& Rocco, 2017) and ultimately may even turn negative (Forster, Bol, \& van de Werfhorst, 2016; Hampf \& Woessmann, 2017; Hanushek et al., 2017; Lavrijsen \& Nicaise, 2017). Furthermore, a number of studies found a similar initially positive but declining relative effect of vocational education on earnings (Cörvers, Heijke, Kriechel, \& Pfeifer, 2011; Golsteyn \& Stenberg, 2017; Lavrijsen \& Nicaise, 2017). Finally, one study found evidence for positive advantages of vocational education that decline over time with respect to the quality of the job match (Verhaest, Lavrijsen, Van Trier, Nicaise, \& Omey, 2018).

However, several studies report no evidence on such trade-off. Indeed, Malamud and PopEleches (2010) found no effect of vocational education on employment probability and wages and Zilic (2018) and Dustmann, Puhani, and Schönberg (2017) did not find any evidence that vocational education leads to different long-term labour market outcomes compared to general education. Finally, Mane (1999), Adda, Dustmann, Meghir, and Robin (2010) and Bertrand, Mogstad, and Mountjoy (2019) found a non-declining positive effect of vocational education on wages at the start of the professional career. 
Yet, abovementioned studies may not have been able to estimate the causal impact of vocational education on labour market outcomes due to two types of selection effects. First, there may be unobservable differences between students who opt for vocational education and students who do not (Ryan, 2001). If these unobservable differences also impact labour market outcomes, this results in a classic omitted variable bias, distorting the true impact of vocational education on labour market outcomes. Several studies indeed report that vocational education is mostly attended by students with lower ability and motivation (Malamud \& Pop-Eleches, 2010; Altonji, Blom, \& Meghir, 2012; Eichhorst, Rodríguez-Planas, Schmidl, \& Zimmerman, 2012). Malamud and Pop-Eleches (2010) and Zilic (2018) even showed empirically that the observed general-vocational differential in employment outcomes is mainly driven by self-selection into the type of programme. A second bias may be introduced by the dynamic selection that takes place in the educational career. Cameron and Heckman (1998) showed this formally. Intuitively, the dynamic selection bias is brought about by the progressively growing negative correlation between observable characteristics and unobservable characteristics in students' educational career. Indeed, students with adverse observable characteristics only proceed to higher grades and remain in higher tracks (which are mostly the general tracks) if their unobserved endowments are sufficiently favourable. This biases the coefficients of observables - such as whether a student is enrolled in vocational education (Baert \& Cockx, 2013; Cockx et al., 2019).

Many earlier studies examining the relative labour market effects of dual apprenticeship and other vocational programmes have indeed not or to a lesser extent attempted to control for these selection effects, which potentially resulted in biased estimates. While several crosssectional studies controlled for detailed cognitive skill test scores (Forster et al., 2016; Hampf \& Woessmann, 2017; Hanushek et al., 2017; Lavrijsen \& Nicaise, 2017; Verhaest et al., 2018), 
this is unlikely to be sufficient to capture all selectivity. Additionally, also the control for dynamic selection bias is inadequate as they again control only for observable characteristics.

Other studies relied on longitudinal labour market data to avoid a biased estimate of the relative change of the effect of vocational programmes (compared to more general programmes) over time (Mane, 1999; Korpi et al., 2003; Cörvers et al., 2011; Brunello \& Rocco, 2017; Golsteyn \& Stenberg, 2017). Although these studies adequately measure the relative change in the effect of vocational versus general programmes on labour market outcomes over time, they do not necessarily control for potential unobserved characteristics that determine enrolment in these programmes or for dynamic selection bias.

Just a few studies have addressed abovementioned selection problems in a more indepth manner by means of quasi-experimental identification strategies. For instance, Malamud and Pop-Eleches (2010), Zilic (2018), and Bertrand et al. (2019) relied on a regression discontinuity design and Dustmann et al. (2017) exploited a natural experiment with respect to track choice. Parey (2016) assessed labour market outcomes at ages 23 and 26 based on an instrumental variable analysis. ${ }^{3}$ However, these quasi-experimental methods hinge on the crucial assumption of the adequateness of the assignment cut-off or exclusion restriction. Consequently, estimates from these analyses can only be given a causal interpretation when these specific assumptions hold, necessitating the comparison of results from different studies relying on different assumptions. Additionally, studies using quasi-

\footnotetext{
${ }^{3} \mathrm{~A}$ few other studies on the effects of vocational education adopted quasi-experimental designs as well, but are less relevant in the context of our paper. Both Oosterbeek and Webbink (2007) and Fersterer, Pischke, and WinterEbmer (2008) assessed the labour market effects of additional years of vocational education and apprenticeship training (i.e. in comparison to no additional years of education), while our focus is rather on the effects of vocational and apprenticeship programmes relative to other programmes that are similar in terms of curriculum length. Further, Verhaest and Baert (2018) focused on higher education, while the focus of the present study and most of the literature in this respect is on vocational education in secondary education.
} 
experimental methods are only able to estimate a local average treatment effect (LATE) (Angrist, Graddy, \& Imbens, 2000), i.e. they are only able to estimate a treatment effect for students affected by the cut-off or instrument.

Finally, Adda, Dustmann, Meghir, and Robin (2010) estimated a similar dynamic model as us to investigate the effect of apprenticeship training on later wages in the German education system. However, they examined this for only a very particular group of students, i.e. only for male students who were in the vocational track at age 10 and who chose whether or not to follow apprenticeship training at age 16. For these students they found a positive effect of apprenticeship training on wages.

In our study, we also employ a dynamic model. In contrast with cross-sectional studies, this model allows us to explicitly control for unobservable differences between students opting for dual apprenticeship programmes and students not opting for dual apprenticeship programmes - based on assumptions outlined in Subsection 5.1. Additionally, by jointly modelling students' schooling careers (already from age six onwards) and early labour market careers in the spirit of Cameron and Heckman (1998), we are also able to control for dynamic selection bias. Moreover, in comparison to studies using RDD and IV which are only able to estimate a local average treatment effect (LATE), we are able to identify a general average treatment effect (ATE). Indeed, while studies using RDD and IV require additional assumptions to extrapolate their results to a general average treatment effect, our methodological approach allows us to directly identify a general average treatment effect without the need to make further assumptions. Finally, in comparison to Adda et al. (2010), we identify this general average treatment effect for the broadest set of students possible, i.e. for all male and female students in the Flemish education system and not only for male students who were in the vocational track at age 10. 
Although we have no intention to claim that our method is superior to the aforementioned quasi-experimental methods used in earlier studies, we believe results from our dynamic approach are highly complementary to those used earlier in the literature on vocational education. Indeed, it allows to verify whether the effect of dual apprenticeship programmes on early labour market outcomes is robust using a different method and therefore relying on different assumptions.

\section{Institutional setting}

In this section, we discuss some crucial characteristics of the education system in Flanders (the Northern, Dutch-speaking region of Belgium), as this is the region from where we obtained our data. The education system in Flanders is depicted schematically in Figure 3. In Flanders, there is compulsory education from September 1st of the year in which a child reaches age 6 . However, before the start of compulsory education almost all children $(98.6 \%$ in the school year 2016-2017) already attend pre-school education from age 2.5 on. Compulsory education ends on June 30th of the year in which a child reaches age 18 or their 18th birthday, whichever comes first. Additionally, there is compulsory full-time school-based education until age 16 or until age 15 if a student has already completed the first two years of secondary education. From that moment on, students are allowed to start dual programmes, which consist of learning on a part-time basis at a school or training centre that may be combined with a part-time apprenticeship in a firm or organisation. In comparison with full-time school-based education where students follow more general courses, the dual programmes are vocationally oriented and are designed to teach a craft to the enrolled 
student.

\section{< Figure 3 about here >}

There are two types of dual programmes that are part of the formal secondary education and training system in Flanders. First, students can enrol in so-called Deeltijds BeroepsSecundair Onderwijs, which is part-time vocational education organised by the Centres for Part-time Education (CPE). ${ }^{4}$ In this programme, students follow classes in a CPE for two days a week. The remaining three days they are either employed as an apprentice or follow a preliminary phase in a Centre for Part-time Training (PTE) to develop their attitudes and skills before starting an apprenticeship. Based on whether students combine classes with an actual apprenticeship, we label this dual programme school-based dual programme with apprenticeship or school-based dual programme without apprenticeship.

Second, students can choose to start the so-called Leertijd, an apprenticeship-based programme that is organised by the Flemish Agency for Entrepreneurial Training (SYNTRA) which is recognised by the Flemish government. In these programmes, students follow theoretical training in a SYNTRA training centre for one day a week, consisting of four hours of general education and four hours of vocational training. The four remaining days they follow practical training with an employer. This dual programme always has an apprenticeship component. Therefore, for brevity, we label this programme simply as training centre-based dual programme, instead of the longer training centre-based dual programme with apprenticeship.

For most fields of study (such as construction, metalworking, woodworking) students can

\footnotetext{
${ }^{4}$ The CPEs are often affiliated to a secondary education school and are governed by one of the educational providers that also govern standard schools.
} 
freely choose to enrol either in the school-based dual programme or in the training centrebased dual programme. Additionally, enrolment in these fields of study is to a great extent equally distributed between the two types of dual programmes. Still, there are two main differences between students enrolled in school-based and training centre-based dual programmes (both with apprenticeships). First, the on-the-job training is more intensive in the training centre-based dual programme (four days a week) than in the school-based dual programme (three days a week). Second, in the training centre-based dual programme a more profound role is given to employers in the organisation and design of the on-the-job training (as in traditional dual system countries like Germany), while this is more driven by the school in the school-based dual programme.

Students who complete full-time school-based education are unconditionally allowed to start tertiary education. In contrast, students who only complete a dual programme receive a secondary education qualification but are not allowed to enrol in tertiary education programmes. The first three years of tertiary education consist either of obtaining an academic Bachelor's degree or professional Bachelor's degree. Then, students who obtained an academic Bachelor's degree can go on to obtain a Master's degree, which requires one or two additional years of studying, dependent on the programme.

\section{Data}

\subsection{Sample}

The econometric model outlined in Section 5 is estimated using the SONAR data. These data were created to study the transition from school to the labour market in Flanders and 
therefore contain exceptionally rich data on schooling and early labour market outcomes for Flemish youths. Concretely, SONAR includes data on three cohorts of about 3,000 individuals born in 1976, 1978, and 1980. These individuals were interviewed at ages 23, 26, and 29. In this study, we use data on the last two cohorts, as for these individuals uniform information on their schooling and early labour market career was available. ${ }^{5}$ To have a sample of pupils with a homogeneous education background, we excluded students who (i) already experienced more than one year of retention at the start of primary education, (ii) needed special help and were therefore in special schools, ${ }^{6}$ and (iii) enrolled in a dual programme for the first time after the age of $18 .^{7}$ Additionally, we excluded students with erroneous or inconsistent data. The final sample consists of 5,541 individuals.

Among the 5,541 students observed in our full sample, 332 (6.0\%) left full-time schoolbased education for a dual programme. Of the latter group, 37.7\% (i.e. 125/332) opted for a training centre-based dual programme, while the remaining 62.3\% (i.e. 207/332) opted for the school-based dual programme. Overall, the number of students who enrol in dual programmes (332) is somewhat small. Consequently, in our estimations the standard errors associated to the coefficients capturing the effect of dual programmes on our outcomes of interest are relatively high. As a consequence, the magnitude of effects presented in the results section should be interpreted with care.

\footnotetext{
${ }^{5}$ Conclusions remain the same when we control with a dummy variable for the two cohorts.

${ }^{6}$ E.g. due to physical and/or mental disability, serious behavioural and/or emotional problems, or serious learning difficulties.

${ }^{7}$ Conclusions remain the same when including these students.
} 


\subsection{Exogenous variables}

In our econometric model, we use six strictly exogenous background characteristics of the students: (i) gender, (ii) migration background, ${ }^{8}$ (iii) number of siblings, (iv and v) maternal and paternal education level (in years of education after primary education), and (vi) day of birth within the calendar year. The first five variables are standard and have also been included by other researchers (Cameron \& Heckman, 2001; Belzil \& Poinas, 2010; Baert \& Cockx, 2013). The day of birth is included to control for relative age within the birth cohort, which is found to positively affect cognitive and non-cognitive achievements in both the short and long term (Angrist \& Krueger, 1991; Bedard \& Dhuey, 2006; Baert \& Cockx, 2013; Fumarco \& Baert, 2019). The summary statistics for these variables can be found in Panel A of Table 1 . When we compare students with full-time school-based education to students who enrolled in a dual programme, we see that males, students with a migration background, students with a higher number of siblings, and students with less-educated parents are overrepresented in the latter sample. Given the substantial overrepresentation of male students in dual programmes, we examine in Section 6 whether the effect of a dual programme is heterogeneous by gender. ${ }^{9}$ This has not been done before in the existing literature using a dynamic model. Indeed, the only other study estimating a dynamic model in this literature - Adda et al. (2010) - only examined male students.

\section{$<$ Table 1 about here >}

Besides controlling for these personal characteristics, for each endogenous outcome

\footnotetext{
8 This was measured as a dummy capturing a foreign nationality of the maternal grandmother.

${ }^{9}$ Although also students with a migration background are overrepresented in a dual programme, we do not pursue the heterogeneity between students with and without a migration background, as the number of students in the former group is too small to estimate this heterogeneity.
} 
(infra, Subsection 4.3) modelled in our econometric estimation we include the unemployment rate at the district level at the moment of these outcomes (source: Public Employment Agency of Flanders). This way, we aim to control for time-varying labour market conditions and (to some extent) for the economic differences by region (and, thereby, family wealth).

\subsection{Endogenous variables}

In our econometric estimation, we jointly model twelve endogenous outcomes: students' (i) delay at the start of primary education, (ii) delay at the start of secondary education, (iii) track choice at the start of the second year of secondary education (either general track, technical or arts track, or vocational track), ${ }^{10}$ (iv) secondary education experience (in terms of whether students experience study delay and/or downgrade) $)^{11}$ at the end of compulsory full-time school-based education, (v) enrolment in a dual programme, and if so, (vi-vii) the kind of dual programme (training centre-based versus school-based (with or without apprenticeship in case of a school-based dual programme)). Additionally, we model whether students (viii) obtained a secondary education qualification, (ix) enrolled in tertiary education, and ( $\mathrm{x}$-xii) were employed three months, one year, and five years after leaving the formal education and

\footnotetext{
${ }^{10}$ Students have to make their track choice after successful completion of the first year of secondary education.

${ }^{11}$ At the end of each academic year during secondary education, students receive an A, B, or C evaluation. Those getting an $A$ are promoted to the next education year. However, if they wish, they can downgrade tracks. In the present article, we define a downgrade as a transition from general secondary education to another track or from technical or arts secondary education to vocational secondary education. Transitions in the opposite direction are hardly observed. Students obtaining a $\mathrm{C}$ must repeat the education year and, if they wish, can downgrade tracks. Students with a B evaluation are forced to downgrade in case they want to be promoted to the next education year (Cockx, Picchio, \& Baert, 2019).
} 
training system. ${ }^{12}$ With respect to the labour market outcomes, in an analogous, parallel model we estimate whether students ( $\mathrm{x}$-xii) secured a permanent contract again three months, one year, and five years after leaving formal education and training (in comparison to being either not employed or employed without a permanent contract). For students in full-time school-based education who decided to pursue tertiary education, 'after leaving education' is defined as after leaving tertiary education - by obtaining a tertiary education qualification or by dropping out of tertiary education before that. By examining students' employment outcomes at three different moments after leaving education, we are able to say something about the - short-term - evolution of the impact of dual programmes on employment outcomes

Descriptive statistics of these endogenous variables are given in Panel B of Table 1. Comparing students in full-time school-based education with students in a dual programme, we see indications that students in the latter group performed worse in school by the end of compulsory full-time school-based education. Indeed, they more often had a delay at the start of primary and secondary education, were more delayed, and downgraded more.

Students enrolled in dual programmes less often obtained a secondary education qualification compared to students in full-time school-based programmes. When we look at the transition to the regular labour market, students in dual programmes more often had a job three months after leaving education. Contrarily, they were less often employed one year or five years after leaving education. This pattern is also observed when looking at the alternative labour market outcomes 'permanent contract after leaving education'. These

\footnotetext{
12 Dual programmes are considered to be part of one's educational and not one's (regular) labour market career. Therefore, these labour market outcome variables only pertain to regular jobs and not to apprenticeship jobs conducted during one's participation in a dual programme.
} 
observations are in line with the theoretical arguments outlined in Section 1 and with the empirical evidence outlined in Section 2 which suggest that dual programmes offer shortterm advantages on the labour market at the cost of long-term disadvantages.

However, by simply comparing the descriptive statistics for students in and out of dual programmes, we are unable to deduce the causal impact of these programmes on labour market outcomes. Indeed, the observed association may also be biased by observable or unobservable differences between students in and out of dual programmes. Additionally, it may be biased by the dynamic selection which occurs in the educational career. Therefore, in the next section we introduce our econometric model which aims to control for both these potential selection biases.

\section{Method}

In this section, we present the econometric model used to estimate the causal impact of leaving full-time school-based education for one of the two dual programmes organised in the Flemish education system on early labour market outcomes. The added value of this approach is twofold. First, it enables us to control for (i) unobservable factors that influence both the enrolment of students in dual programmes and later employment outcomes and (ii) dynamic selection in the educational career. Second, this model allows us to make a distinction between the direct effect of these dual programmes (conditional on their potential effect on later schooling outcomes) and their indirect effect (through these potentially altered schooling outcomes). 


\subsection{Dynamic discrete choice model}

Our model is a dynamic discrete choice model. Cameron and Heckman (1998; 2001) introduced this type of model to control for the dynamic selection in the educational career. This approach has been applied and refined by, among others, Belzil and Poinas (2010), Baert and Cockx (2013), Baert, Neyt, Omey, and Verhaest (2017), and Cockx et al. (2019). As mentioned in Section 2, Adda et al. (2010) used this framework to examine the impact of apprenticeship training on later wages. We improve their strategy by minimising our model's initial conditions problem (infra).

In line with this literature, our model is a sequence of binary and multinomial probabilities. More concretely, in our benchmark model, we jointly estimate the twelve outcomes mentioned in Subsection $4.3 .{ }^{13}$ See Figure 4 for a schematic overview of this model. ${ }^{14}$

\section{< Figure 4 about here >}

The choice set for a specific outcome, denoted by $C^{0}$, is a set of multinomial numbers: $C^{O}=\left\{0,1, \ldots, n^{0}\right\}$, where $n^{0}$ defines the number of choices that can be made for outcome $O$ minus 1 . With respect to outcome (iii), three outcome values are possible: general track (outcome value 0), technical or arts track (outcome value 1), and vocational track (outcome value 2). With respect to outcome (iv), four outcome values are possible: no retention and no downgrade (outcome value 0), retention but no downgrade (outcome value 1), no retention

\footnotetext{
${ }^{13}$ It would also have been possible to start the model from the outcome 'delay at the start of secondary education' and use 'delay at the start of primary education' as explanatory variable for this outcome. However, conclusions remain the same when we use 'delay at the start of secondary education' as the first modelled outcome.

${ }^{14}$ As mentioned in Subsection 4.3, in an analogous, parallel model we investigate the impact of dual programmes on the chances of securing a permanent contract. The last three outcomes then become whether students had a permanent contract three months, one year, and five years after leaving education.
} 
but downgrade (outcome value 2), and retention and downgrade (outcome value 3). All other outcomes are binary in nature.

The optimal choice $\hat{c}_{i}^{O}$ of an individual $i$ with respect to outcome $O$ is the following:

$$
\hat{c}_{i}^{0}=c \in C^{0} \quad \text { if } \quad \omega_{c}^{0}<U_{i, c}^{0} \leq \omega_{c+1}^{O},
$$

where $U_{i, c}^{O}$ is the latent utility of choice $c$ for outcome $O$, and $\omega_{c}^{O}$ and $\omega_{c+1}^{O}$ are threshold utilities ('cut-off values') that determine the ordered choice $\left(\omega_{0}^{O} \equiv-\infty\right.$ and $\left.\omega_{n^{O}+1}^{O} \equiv+\infty\right)$. In line with the literature, we approximate this $U_{i, c}^{0}$ by a linear index:

$$
U_{i, c}^{O}=Z_{i} \alpha^{0}+R_{i}^{O} B^{O}+V_{i}^{O} \gamma^{O}+v_{i, c}^{O}
$$

In this equation, $Z_{i}$ is a vector representing the exogenous variables as observed for individual $i$, and $R_{i}^{O}$ captures the unemployment rate at the district level at the moment of outcome $O$, both of which are described in Subsection 4.2. $V_{i}^{O}$ is the vector of endogenous outcomes that are realised before outcome $O$, which are described in Subsection 4.3. The vectors $\alpha^{0}, \theta^{0}$, and $\gamma^{O}$ are vectors of associated parameters and $v_{i, c}^{O}$ is unobservable from the researcher's point of view.

We follow Cameron and Heckman (2001) by assuming that $v_{i, c}^{O}$ is characterised by a factor structure. However, in line with the more recent literature (Carneiro, Hansen, \& Heckman, 2003; Heckman \& Navarro, 2007; Fruehwirth, Navarro, \& Takahashi, 2016; Cockx et al., 2019), we generalise by allowing the factor "loadings" to depend on our main treatment status (whether students enrolled in a dual programme) $P_{i}$ :

$$
v_{i, c}^{o}=\delta^{o} \eta+\varphi^{o} P_{i} \eta+\varepsilon_{i, c}^{o}
$$


in which $\eta$ is a random effect, independent of $\varepsilon_{i, c}^{O}$ and independent across individual students, which captures determinants that are unobserved and assumed to be independent of the observed exogenous student characteristics $\left(Z_{i}\right.$ and $\left.R_{i}^{O}\right) .{ }^{15}$ The outcome-specific coefficients $\delta^{O}$ and $\varphi^{O}$ are normalised to 1 for the first modelled outcome. The error term $\varepsilon_{i, c}^{O}$ is i.i.d. and assumed to be logistically distributed.

As a consequence, we can write the probability of a particular outcome value as:

$$
\begin{aligned}
& \operatorname{Pr}\left(\hat{c}_{i}^{O}=c \mid \mathrm{Z}_{\mathrm{i}}, R_{i}^{O}, V_{i}^{o}, \eta ; \vartheta\right)=\frac{\exp \left(\omega_{c+1}^{o}-\mathrm{Z}_{\mathrm{i}} \alpha^{O}-R_{i}^{o} \beta^{O}-V_{i}^{o} \gamma^{o}-\delta^{o} \eta-\varphi^{o} P_{i} \eta-\varepsilon_{i, c}^{o}\right)}{1+\exp \left(\omega_{c+1}^{O}-\mathrm{Z}_{\mathrm{i}} \alpha^{O}-R_{i}^{O} \beta^{O}-V_{i}^{O} \gamma^{O}-\delta^{o} \eta-\varepsilon_{i, c}^{O}\right)} \\
& -\frac{\exp \left(\omega_{c}^{O}-\mathrm{Z}_{\mathrm{i}} \alpha^{\mathrm{O}}-R_{i}^{O} \beta^{O}-V_{i}^{O} \gamma^{O}-\delta^{o} \eta-\varphi^{o} P_{i} \eta-\varepsilon_{i, c}^{O}\right)}{1+\exp \left(\omega_{c}^{O}-\mathrm{Z}_{\mathrm{i}} \alpha^{O}-R_{i}^{o} \beta^{O}-V_{i}^{O} \gamma^{O}-\delta^{o} \eta-\varepsilon_{i, c}^{O}\right)}
\end{aligned}
$$

in which we denote the vector of unknown parameters by $\vartheta$. The likelihood contribution $\ell_{i}\left(Z_{i}, R_{i}^{O}, V_{i}^{O}, \eta ; \vartheta\right)$ for any sampled individual, conditional on the unobservable $\eta$, is then constructed by the product of the probabilities of the choices realised in the data for the twelve modelled outcomes.

Following the literature, we adopt a non-parametric discrete distribution for the unobserved random variable $\eta$. We assume that this distribution is characterised by an $a$ priori unknown number of $K$ points of support $\eta_{k}$ to which are assigned probabilities $p_{k}(q)$ specified as logistic transforms:

$$
p_{k}(q)=\frac{\exp \left(q_{k}\right)}{\sum_{j=1}^{K} \exp \left(q_{j}\right)} \text { with } k=1,2, \ldots K ; q \equiv\left[q_{1}, q_{2}, \ldots, q_{k}\right]^{\prime} \text { and } q_{1}=0 \text {. }
$$

Hence, the unconditional individual likelihood contribution for individual $i$ is:

\footnotetext{
${ }^{15}$ As a consequence of this modelling assumption, the coefficients of $Z_{i}$ and $R_{i}^{O}$ cannot be given a causal interpretation. However, given that these coefficients are not the focus of our study, this is not problematic.
} 


$$
\ell_{i}\left(Z_{i}, R_{i}^{O}, V_{i}^{O} ; \vartheta, q\right)=\sum_{k=1}^{K} p_{k}(q) \ell_{i}\left(Z_{i}, R_{i}^{O}, V_{i}^{O}, \eta_{k} ; \vartheta\right)
$$

As Cameron and Heckman (1998; 2001) and Keane, Todd, and Wolpin (2011) show, identification of the causal effect requires to address a so-called initial conditions problem. Participation in dual apprenticeship programmes is part of a broader educational participation process with subsequent choices potentially being affected by serially correlated shocks. Therefore, an assumption has to be made about when the process has been initialised. In our model this assumption is considerably weaker compared to similar assumptions made in studies using comparable models, because our model starts much earlier in the student's educational career. Indeed, our model begins at the start of primary education - which occurs at age six - and even at that moment we already model variation in the years of study delay. In comparison, the only other study that uses a dynamic model to estimate the impact of vocational education on labour market outcomes - Adda et al. (2010) - only start their model at age 16.

\subsection{Model selection}

We estimated the coefficients for the model presented in the previous subsection with a maximum likelihood estimation following Gaure, Røed, and Zhang (2007). Heterogeneity types were gradually added until the log-likelihood value of the model failed to increase.

Table A-1 reports the number of parameters, the log-likelihood, and the Akaike Information Criterion $(\mathrm{AIC})^{16}$ values of the model according to the number of heterogeneity

\footnotetext{
${ }^{16}$ Following the argument in Gaure et al. (2007), we believe that the AIC is the preferable criterion for our sample size.
} 
types $K$ included. The lowest AIC was obtained for $K=6$. The coefficient estimates for this model are displayed in Table A-2. Unless otherwise stated, the simulations below are based on these parameter estimates.

The coefficient estimates in Table A-2 provide further evidence that controlling for unobserved heterogeneity is important. First, the proportion of each of the six heterogeneity types is substantial $\left(p_{1}=40.1 \%, p_{2}=6.0 \%, p_{3}=35.4 \%, p_{4}=16.5 \%, p_{5}=0.9 \%\right.$, and $\left.p_{6}=1.2 \%\right) .{ }^{17}$ Second, almost all (other) parameters of the unobserved heterogeneity distribution (i.e. all $\eta_{k}{ }^{\prime}$ s and most $\delta^{0}$ 's) are highly significantly different from 0.

\subsection{Simulation strategy}

Based on the estimated parameters of our preferred model, we simulate student schooling careers (among which their enrolment in dual programmes) and early labour market outcomes. To answer our research questions, we run these simulations under different scenarios with respect to students' enrolment in dual programmes.

For each analysis, we randomly draw 999 vectors from the asymptotic normal distribution of the preferred model's parameters. Subsequently, in each of the 999 draws, the parameters are used to calculate the probabilities associated with each heterogeneity type. These probabilities are then used to randomly assign a heterogeneity type to each pupil in the sample. Thereafter, based on these randomly drawn parameters and the assignment of individuals to a heterogeneity type, the full sequence of education and labour market outcomes is simulated for each student in the sample (for each draw).

\footnotetext{
${ }^{17}$ For instance, following Equation (5), $\mathrm{p}_{2}=\exp (-1.899) /(\exp (0)+\exp (-1.899)+\exp (-0.124)+\exp (-0.887)+\exp (-$ $3.787)+\exp (-3.538))$
} 
More concretely, each outcome is simulated sequentially based on its (multinomial) logit specification, reported in Subsection 5.1. These specifications yield, for each individual in each draw, a probability for each potential outcome value. These probabilities are then translated to segments on the unit interval. To determine the particular outcome value for each individual in each draw, a random number is generated from the standard uniform distribution. The outcome value assigned to the individual depends on the segment in which this random number falls. Once an outcome is assigned, it is saved and conditioned upon for subsequent outcomes. In the sequel, the model prediction of a particular outcome refers to the average of these 999 replications. The 95\% confidence intervals are constructed by choosing the appropriate percentiles of the 999 simulated probabilities.

\subsection{Goodness of fit}

To determine the benchmark model's goodness of fit, for each endogenous variable we compared the actual probability (as observed in our data) with the simulated probability (as estimated by our model). As can be seen from Figure 5 and Table A-3, the simulated probabilities are closely distributed around the actual probabilities. Only for the outcome 'Employed five years after leaving education' does the simulated probability deviates significantly (at the $5 \%$ confidence level) from the actual probability. Nonetheless, also for this outcome the simulated probability approaches the actual probability quite well in economic terms (i.e. the probabilities are 0.923 and 0.906, respectively).

\section{$<$ Figure 5 about here >}




\subsection{Average Treatment Effects (ATEs)}

To answer our research questions, we simulated, following the strategy presented in the previous subsection, two series of average treatment effects (ATEs): one for the treatment 'training centre-based dual programme' and one for the treatment 'school-based dual programme with apprenticeship'. Since in a school-based dual programme without apprenticeship there is no real work component (supra, Section 3), we do not report the ATEs for this programme. The ATEs for this programme are available on request.

The ATEs are a combination of average treatment effects on the treated (ATTs) and average treatment effects on the non-treated (ATNTs). ATTs were based on the simulated outcomes of individuals ('ind.' in the following equations) who were assigned to the treatment of a certain dual programme given a particular parameter draw. Similarly, we calculated the ATNTs for individuals who were assigned to no treatment. First, the ATT for a certain treatment is calculated for each outcome of interest (and for each of the 999 parameter draws) as follows:

$$
A T T=\frac{\text { average outcome across treated ind. }}{\text { average outcome across treated ind., in the counterfacutal of no treatment }}
$$

The counterfactual outcomes were realised by forcing all indicator variables for treatment (i.e. participation in dual programme, school-based dual programme, and apprenticeship during school-based dual programme) to 0 for each treated individual. Second, the ATNT is calculated for each outcome of interest as follows:

$$
A T N T=\frac{\text { average outcome across untreated ind., in the counterfacutal of treatment }}{\text { average outcome across untreated ind. }} .
$$

In this case, the counterfactual outcomes in case of treatment were realised by forcing the indicator variables for treatment to the appropriate status. More concretely, in the 
counterfactual situation of a training centre-based dual programme, only the variable 'participation in dual programme' was forced to 1 , while in the counterfactual situation of a school-based dual programme with apprenticeship, also 'school-based dual programme' and 'apprenticeship during school-based dual programme' were forced to 1 for each untreated individual. Third, the ATE is realised by combining both strategies and are calculated as follows:

$$
A T E=\frac{\text { average outcome across treated ind }}{\text { average outcome across untreated ind }} .
$$

For each parameter draw, the numerator is the average outcome in case of treatment for all individuals (so the factual simulated outcome for the individuals assigned to the treatment or the counterfactual simulated outcome in case of no such assignment), while the denominator is the average outcome in case of no treatment for all the individuals (so the counterfactual simulated outcome for the individuals assigned to the treatment or the factual simulated outcome in case of no such assignment). If the ATE is above (below) 1 , this means there is a positive (negative) effect of the treatment on the outcome of interest. Below, we discuss the distribution of this ATE, i.e. its average over the 999 draws and its $95 \%$ confidence intervals.

\subsection{Total, direct, and indirect effects}

For all schooling and labour market outcomes realised after the decision (not) to enrol in a dual programme, we make a distinction between total effects, direct effects, and indirect effects. For the total effects, we do not condition the denominator of equation (9) on earlier outcomes as would be realised in the scenario of treatment (enrolling into a certain dual programme). As a consequence, the treatment impacts the outcomes of interest both directly (via the model's coefficients capturing the direct effect of enrolling into a dual programme) 
and indirectly (via the model's coefficients capturing the effect of earlier outcomes, which in turn were (potentially) affected by enrolling into a dual programme). Therefore, these total effects can also be labelled as 'unconditional effects', i.e. effects without keeping former schooling and labour market outcomes fixed to those of the treatment group.

For the direct effects, in contrast, we do condition the denominator of equation (9) on earlier outcomes as would be realised in the scenario of treatment (enrolling into a certain dual programme). As a consequence, the treatment impacts the outcomes of interest only directly (via the model's coefficients capturing the direct effect of enrolling into a dual programme). Therefore, these direct effects can also be labelled 'conditional effects', i.e. effects while keeping former schooling and labour market outcomes fixed to those of the treatment group.

The indirect effects are calculated as the average differences between the total effects and the direct effects over all draws of the simulations (supra, Subsection 5.3). The indirect effects capture the impact of the treatment through earlier schooling and labour market outcomes (via the model's coefficients capturing the effect of earlier outcomes, which in turn were (potentially) affected by enrolling into a dual programme).

\section{Results}

In this section we present the results of our analyses. We start with a brief discussion of the coefficient estimates of our benchmark model and three alternative models (to inspect whether the effects of the dual programmes are heterogeneous by observed early labour market outcome and by gender). Next, we discuss our ATEs and contrast the total effects of 
enrolling into a dual programme with its direct effects. Then, we compare the labour market outcome 'employed after leaving education' with the alternative labour market outcome 'permanent contract after leaving education'. Finally, we directly compare the two dual programmes with each other. All these analyses are based on our preferred model, i.e. the model with six heterogeneity types.

Table 2 shows the main coefficient estimates for several specifications of our model - the full estimation results of our benchmark model are presented in Table A-2. The models for which the main results are presented in the first two columns of Table 2 use 'employed after leaving education' as the labour market outcome, while the other models use 'permanent contract after leaving education'. Column (1) and (3) show the results for models without an interaction effect between participation in a dual programme and female gender, while column (2) and (4) provide the estimation results for an extended version of the model in which this interaction is added. The coefficients should be interpreted relative to 0 . If the coefficients are above (below) 0 , there is a positive (negative) effect of enrolling into a dual programme compared to enrolling into full-time school-based education. The effect of enrolling into a training centre-based dual programme is measured by the coefficient of 'participation in dual programme'. For students in a school-based dual programme without apprenticeship (with apprenticeship), this coefficient should be increased with the coefficient of 'school-based dual programme' (with the coefficients of 'school-based dual programme' and 'apprenticeship during school-based dual programme').

\section{$<$ Table 2 about here $>$}

We first focus on the results in column (1) and (3). Panel A of Table 2 clearly shows a highly significantly negative effect of enrolling into any dual programme on the probability of obtaining a secondary education qualification. We cannot reject that this effect is 
homogeneous by whether one enrols into a training centre-based or school-based dual programme (i.e. 'school-based dual programme' is not significant) or by whether one is employed during one's school-based dual programme (i.e. 'apprenticeship during schoolbased dual programme' is not significant).

Regarding work status (employment and having a permanent contract) three months after leaving formal education and training (Panel B), we observe a highly significantly positive effect for students doing a training centre-based dual programme (conditional on the included education outcomes). For students with an experience of a school-based dual programme, we cannot reject the null hypothesis of no effect (i.e. the sum of the coefficients of 'participation in dual programme' and 'school-based dual programme' was not statistically significantly different from 0). Further, no significant effects of the dual programmes were found with respect to the later labour market outcomes (conditional on earlier education and labour market outcomes).

Concerning heterogeneous effects by gender, we find a negative effect of the interaction term 'participation in dual programme $\times$ female gender' on the probability of being employed three months after leaving formal education and training but not on the probability of having a permanent contract after three months. So, the premium of a dual programme is found to be lower for females, ceteris paribus. ${ }^{18}$

The abovementioned results based on parameter estimates are direct effects, i.e. they are conditional on all earlier outcomes. Additionally, their magnitude is difficult to interpret. ${ }^{19}$

\footnotetext{
18 Conclusions remain the same when the model is run separately for males and females.

19 This difficulty in interpretation has two reasons. First, coefficient estimates from logistic regressions cannot directly be interpreted as marginal effects. Second, as described in the second paragraph of this section, for certain dual programmes, multiple coefficients must be combined to assess the effect of the dual programme.
} 
Therefore, in Table 3 and Table 4, we present various ATEs of the dual apprenticeship programmes, the treatment being a particular dual apprenticeship programme. ${ }^{20}$ The counterfactual is the scenario where the same individuals do not follow any dual apprenticeship programme (i.e. they are enrolled in full-time school-based education). The ATEs should be interpreted relative to 1 . If the ratio is above (below) 1 , there is a positive (negative) effect of the dual programme compared to full-time school-based education.

Column (1) of Table 3 shows the total effects of dual apprenticeship programmes on obtaining a secondary education qualification and employment three months, one year, and five years after leaving education. In line with our discussion of Panel A of Table 2, we find that students doing a training centre-based dual programme (Panel A of Table 3) are 5.5\% less likely to obtain a secondary education qualification compared to students in full-time school-based education. Additionally, students in a school-based dual programme with apprenticeship (Panel B of Table 3) are 3.9\% less likely to obtain this qualification (compared to students who did not enrol in a dual programme). However, the latter effect is not significantly different from 0 . Concerning the labour market outcomes, we find that students in training centre-based dual programmes are $29.7 \%$ more likely to have a job three months after leaving formal education and training, but that this effect fades over time; that is, there is no effect on the probability of having a job one year and five years after leaving education. For students doing a school-based dual programme with apprenticeship we see the same pattern, although we do not find a statistically significant effect. In economic terms, the ATEs for these students are lower too (compared to those for a training centre-based dual programme).

\footnotetext{
${ }^{20}$ Results do not substantially differ when estimating ATTs or ATNTs (see Table A-4).
} 


\section{$<$ Table 3 about here >}

Column (2) of Table 3 presents the direct effects of the two dual programmes. ${ }^{21}$ These effects capture the same empirical pattern as that presented in column (1) of Table 2, since the coefficient estimates also measure direct effects. For students doing a training centrebased dual programme, the direct effect on finding a job three months after leaving education (30.6\%) is slightly bigger than the total effect $(29.7 \%)$. This suggests that the direct effect overcompensates for a small negative indirect effect (depicted in column (3)). This negative indirect effect $(-0.9 \%)$ stems from the negative effect of doing a training centre-based dual programme on obtaining a secondary education qualification (supra), which in turn has a positive effect on finding work three months after leaving education (Panel M of Table A2). ${ }^{22,23}$ The fact that the positive total effect of a training centre-based dual programme on employment outcomes three months after leaving education is completely driven by the direct effect, provides evidence that it is the experience of doing a training centre-based dual programme per se that increases employment opportunities and not because of potentially altered schooling outcomes. The positive indirect effect of a training centre-based dual programme one year after leaving education stems from the positive effect of a training centre-based dual programme on the probability of having a job three months after leaving education (supra) which - naturally - in turn has a positive effect on the probability of having

\footnotetext{
21 Given that for the outcome 'secondary education qualification obtained' we do not condition on prior endogenous outcome variables, the direct effects equal the total effects and are therefore not reported.

22 When using the outcome 'permanent contract after leaving education', the differences between total effects and direct effects are similar. These additional results are available on request

${ }^{23}$ Although the negative indirect effect is small in magnitude, it is significantly different from zero because for almost all individuals obtaining a secondary education qualification has a positive effect on the probability of having a job three months after leaving education. Therefore, given the negative effect of a training centre-based dual programme on the probability of obtaining a secondary education qualification, for almost all students the direct effect of doing a training centre-based dual programme on the probability of having a job three months after leaving education is bigger than its total effect, leading to a significantly negative indirect effect.
} 
a job one year after leaving education (Panel $\mathrm{N}$ of Table $\mathrm{A}-2$ ).

Table 4 compares the total effects on the labour market outcome 'employed after leaving education' with the alternative labour market outcome 'permanent contract after leaving education'. For this alternative outcome the results are somewhat more pronounced. Students doing a training centre-based dual programme (panel A) have a $78.9 \%$ higher probability of having a permanent contract three months after leaving education and a $26.7 \%$ higher probability of having a permanent contract one year after leaving education. Again, for students in the school-based dual programme with apprenticeship (Panel B), no statistically significant treatment effects are found.

\section{$<$ Table 4 about here >}

Finally, we directly compare the two dual programmes with each other. Table 5 shows the ATEs when comparing a training centre-based dual programme to a school-based dual programme. The findings are in line to those when comparing both of these programmes individually to full-time school-based programmes: a training centre-based dual programme increases the probability of being employed shortly after leaving education but this comes at the cost of lower chances of obtaining a secondary education qualification. Due to the more limited sample size of students in dual programmes, ATEs from this direct comparison do not reach statistical significance at the conventional confidence levels.

\section{$<$ Table 5 about here $>$}

\section{Conclusion}

In this study we examined the effect of participation in training centre-based and school- 
based dual programmes in the context of the Flemish education system on educational achievement and subsequent labour market outcomes. We found that students doing a training centre-based dual programme less often obtain a secondary education qualification compared to students in full-time school-based education, whereas this effect was not significant for students in a school-based dual programme. In addition, students doing a training centre-based dual programme had an increased probability of finding a job when entering the regular labour market but this impact diminished over time. This advantage was not found for students in the school-based dual programme, suggesting that the positive effect of doing a training centre-based dual programme may be due to either its more intensive on-the-job training and/or its closer ties to the labour market. The finding that the advantage of training centre-based dual programmes in the short run fades over time is consistent with previous literature that also found evidence for a positive effect of vocational education on employment outcomes only in the short run (Forster et al., 2016; Brunello \& Rocco, 2017; Hampf \& Woessmann, 2017; Hanushek et al., 2017; Lavrijsen \& Nicaise, 2017).

Based on these findings we formulate two main recommendations for policy makers. A first recommendation is in line with recommendations formulated in earlier studies, namely that the short-term transition from education to the labour market could be improved by promoting vocational programmes. Our finding that only the programme with the most days of on-the-job training significantly increased employment opportunities is in line with findings by Albanese et al. (2017) and suggests that policy makers could enforce the short-term labour market advantage by increasing the extent of on-the-job training in vocational programmes. Our study shows that these recommendations formulated in earlier studies still hold when using a dynamic model which has rarely been used in earlier studies and when examining an institutional setting which has not yet been examined before - Flanders. Second, our results 
indicate that policy makers, however, face a trade-off when deciding on the extent to which on-the-job learning is incorporated in vocational programmes. Indeed, while the dual apprenticeship programme with the most days of on-the-job training improved short-term employment opportunities, it also increased the probability of unqualified drop-out, which may potentially have negative effects beyond early labour market outcomes (Weber, 2014; Hanushek et al., 2017).

Finally, we recommend several directions for future research. First, we suggest investigating the effect of dual apprenticeship programmes (in Belgium and abroad) on other labour market outcomes than those considered in this study. In particular, it would be interesting to see what the direct and indirect causal effects of the studied programmes on later wages and other indicators of job quality are. Second, due to data constraints, we were unable to investigate the mechanisms underlying the smoother transition to the regular labour market after enrolling in a (training centre-based) dual apprenticeship programme during secondary education. In particular, our data did not allow us to examine the extent to which students enrolled in such a programme start their regular labour market career with the employer that they worked for during these programmes. Finding evidence for this screening channel could support the idea that programmes with more on-the-job training are more effective due to the stronger ties with the labour market. Third, since we only observed the first five years after entering the regular labour market, we were not able to assess whether the declining advantage of dual programmes in terms of labour market outcomes ultimately turns into a disadvantage, as found in some other studies. Relying on a similar type of modelling to investigate whether this is the case is another interesting avenue for further research. 


\section{References}

Adda, J., Dustmann, C., Meghir, C., \& Robin, J. M. (2010). Career progression and formal versus on-the-job training. IFS Working Papers, 10/13.

Albanese, A., Cappellari, L., \& Leonardi, M. (2017). The effects of youth labor market reforms: Evidence from Italian apprenticeships. IZA Discussion Papers, 10766.

Altonji, J. G., Blom, E., \& Meghir, C. (2012). Heterogeneity in human capital investments: High school curriculum, college major, and careers. Annual Review of Economics, 4, 185-223.

Angrist, J. D., Graddy, K., \& Imbens, G. (2000). The interpretation of instrumental variables estimators in simultaneous equations models with an application to the demand for fish. Review of Economic Studies, 67, 499-527.

Angrist, J. D., \& Krueger, A. B. (1991). Does compulsory school attendance affect schooling and earnings? Quarterly Journal of Economics, 106, 979-1074.

Baert, S., \& Cockx, B. (2013). Pure ethnic gaps in educational attainment and school to work transitions. When do they arise? Economics of Education Review, 36, 276-294.

Baert, S., Neyt, B., Omey, E., \& Verhaest, D. (2017). Student work, educational achievement, and later employment: A dynamic approach. IZA Discussion Papers, 11127.

Bedard K., \& Dhuey, E. (2006). The persistence of early childhood maturity: International evidence of long-run age effects. Quarterly Journal of Economics, 121, 1437-1472.

Belzil, C., \& Poinas, F. (2010). Education and early career outcomes of second-generation immigrants in France. Labour Economics, 17, 101-110.

Bertrand, M., Mogstad, M., \& Mountjoy, J. (2019). Improving educational pathways to social mobility: Evidence from Norway's "Reform 94". NBER Working Papers, 25679.

Bishop, J. H., \& Mane, F. (2004). The impacts of career-technical education on high school 
labor market success. Economics of Education Review, 23, 381-402.

Brunello, G. (2001). On the complementarity between education and training in Europe. IZA Discussion Papers, 309.

Brunello, G., \& Rocco, L. (2017). The labor market effects of academic and vocational education over the life cycle: Evidence based on a British cohort. Journal of Human Capital, $11,106-166$.

Cameron, S. V., \& Heckman, J. J. (1998). Life cycle schooling and dynamic selection bias: Models and evidence for five cohorts of American males. Journal of Political Economy, 106, $262-333$.

Cameron, S. V., \& Heckman, J. J. (2001). The dynamics of educational attainment for Black, Hispanic and White males. Journal of Political Economy, 109, 455-499.

Carneiro, P., Hansen, K., \& Heckman, J. J. (2003). Estimating distributions of treatment effects with an application to the returns to schooling and measurement of the effects of uncertainty on college choice. International Economic Review, 44, 361-422.

Cockx, B., Picchio, M., \& Baert, S. (2019). Modeling the effects of grade retention in high school. Journal of Applied Econometrics, 34, 403-424.

Cörvers, F., Heijke, H., Kriechel, B., \& Pfeifer, H. (2011). High and steady or low and rising? Life-cycle earnings patterns in vocational and general education. Mimeo.

Dougherty, S. M. (2018). The effect of career and technical education on human capital accumulation: Causal evidence from Massachusetts. Education Finance and Policy, 13(2), $119-148$.

Dustmann, C., Puhani, P., \& Schönberg, U. (2017). The long-term effects of early track choice. Economic Journal, 127, 1348-1380.

Eichhorst, W., Rodríguez-Planas, N., Schmidl, R., \& Zimmermann, K. (2012). A roadmap 
to vocational education and training systems around the world. IZA Discussion Papers, 7110.

Fersterer, J., Pischke, J.-S., \& Winter-Ebmer, R. (2008). Returns to apprenticeship training in Austria: Evidence from failed firms. Scandinavian Journal of Economics, 110, 733-753.

Forster, A. G., Bol, T., \& van de Werfhorst, H. G. (2016). Vocational education and employment over the life cycle. Sociological Science, 3, 473-494.

Fruehwirth, J. C., Navarro, S., \& Takahashi, Y. (2016). How the timing of grade retention affects outcomes: Identification and estimation of time-varying treatment effects. Journal of Labor Economics, 34, 979-1021.

Fumarco, L., \& Baert, S. (2019). Relative age effect on European adolescents' social network. Journal of Economic Behavior \& Organisation, 168, 318-337.

Gaure, S., Røed, K., \& Zhang, T. (2007). Time and causality: A Monte Carlo assessment of the timing-of-events approach. Journal of Econometrics, 141, 1159-1195.

Golsteyn, B. H., \& Stenberg, A. (2017). Earnings over the life course: General versus vocational education. Journal of Human Capital, 11, 167-212.

Grubb, W. N., \& Lazerson, M. (2005). Vocationalism in higher education: The triumph of the education gospel. Journal of Higher Education, 76, 1-25.

Hampf, F., \& Woessmann, L. (2017). Vocational vs. general education and employment over the life cycle: New evidence from PIAAC. CESifo Economic Studies, 63, 255-269.

Hanushek, E. A., Schwerdt, G., Woessmann, L., \& Zhang, L. (2017). General education, vocational education, and labor-market outcomes over the lifecycle. Journal of Human Resources, 52, 48-87.

Heckman, J. J., \& Navarro, S. (2007). Dynamic discrete choice and dynamic treatment effects. Journal of Econometrics, 136, 341-396.

Keane, M. P., Todd, P. E., \& Wolpin, K. I. (2011). The structural estimation of behavioral 
models: Discrete choice dynamic programming methods and applications. In Handbook of Labor Economics, Vol. 4, 331-461. Amsterdam: Elsevier.

Kemple, J. J., \& Scott-Clayton, J. (2004). Career academies: Impacts on labor market outcomes and educational attainment. New York: MDRC.

Korpi, T., De Graaf, P., Hendrickx, J., \& Layte, R. (2003). Vocational training and career employment precariousness in Great Britain, the Netherlands and Sweden. Acta Sociologica, $46,17-30$

Krueger, D., \& Kumar, K. B. (2004). US-Europe differences in technology-driven growth: quantifying the role of education. Journal of Monetary Economics, 51, 161-190.

Lavrijsen, J., \& Nicaise, I. (2017). Returns on vocational education over the life cycle: Between immediate labour market preparation and lifelong employability. International Review of Education, 63, 257-280.

Malamud, O., \& Pop-Eleches, C. (2010). General education versus vocational training: Evidence from an economy in transition. Review of Economics and Statistics, 92, 43-60.

Mane, F. (1999). Trends in the payoff to academic and occupation-specific skills: The short and medium run returns to academic and vocational high school courses for noncollege-bound students. Economics of Education Review, 18, 417-437.

Oosterbeek, H., \& Webbink, D. (2007). Wage effects of an extra year of basic vocational education. Economics of Education Review, 26, 408-419.

Parey, M. (2016). Vocational schooling versus apprenticeship training: Evidence from vacancy data. Mimeo.

Plank, S. B., DeLuca, S., \& Estacion, A. (2008). High school dropout and the role of career and technical education: A survival analysis of surviving high school. Sociology of Education, 81(4), 345-370. 
Rosenbaum, J. E. (2001). Beyond college for all: Career paths for the forgotten half. New York: Russell Sage Foundation.

Ryan, P. (2001). The school-to-work transition: A cross-national perspective. Journal of Economic Literature, 39, 34-92.

Shavit, Y., \& Muller, W. (2000). Vocational secondary education. European societies, 2, 29-50.

van de Werfhorst, H. G. (2014). Changing societies and four tasks of schooling: Challenges for strongly differentiated educational systems. International Review of Education, $60,123-144$.

Verhaest, D., \& Baert, S. (2018). The effects of workplace learning in higher education on employment and match quality: Is there an early-career trade-off? Empirical Economics, 55, $1229-1270$.

Verhaest, D., Lavrijsen, J., Van Trier, W., Nicaise, I., \& Omey, E. (2018). General education, vocational education and skill mismatches: Short-run versus long-run effects. Oxford Economic Papers, 70, 974-993.

Weber, S. (2014). Human capital depreciation and education level. International Journal of Manpower, 35, 613-642.

Wolter, S. C., \& Ryan, P. (2011). Apprenticeship. In Handbook of the Economics of Education, Vol. 3, 521-576. Amsterdam: Elsevier.

Zilic, I. (2018). General versus vocational education: Lessons from a quasi-experiment in Croatia. Economics of Education Review, 62, 1-11.

Zimmermann, K. F., Biavaschi, C., Eichhorst, W., Giulietti, C., Kendzia, M. J., Muravyev, A., Pieters, J., Rodríguez-Planas, N., \& Schmidl, R. (2013). Youth unemployment and vocational training. Foundations and Trends in Microeconomics, 9, 1-157. 


\section{Appendix A}

< Table A-1 about here >

< Table A-2 about here >

< Table A-3 about here >

< Table A-4 about here > 
Table 1. Summary statistics.

\begin{tabular}{|c|c|c|c|c|c|c|c|c|c|c|c|c|}
\hline & (1) & (2) & (3) & (4) & (5) & (6) & (7) & (8) & (9) & (10) & (11) & (12) \\
\hline & \multicolumn{2}{|c|}{ I. Whole sample } & \multicolumn{2}{|c|}{$\begin{array}{l}\text { II. Sample with full- } \\
\text { time school-based } \\
\text { education }\end{array}$} & \multicolumn{2}{|c|}{$\begin{array}{l}\text { III. Sample with dual } \\
\text { programme }\end{array}$} & \multicolumn{2}{|c|}{$\begin{array}{l}\text { IV. Sample with } \\
\text { training centre- } \\
\text { based dual } \\
\text { programme }\end{array}$} & \multicolumn{2}{|c|}{$\begin{array}{l}\text { V. Sample with } \\
\text { school-based dual } \\
\text { programme without } \\
\text { apprenticeship } \\
(\mathrm{N}=97)\end{array}$} & \multicolumn{2}{|c|}{$\begin{array}{l}\text { VI. Sample with } \\
\text { school-based dual } \\
\text { programme with } \\
\text { apprenticeship } \\
(\mathrm{N}=110)\end{array}$} \\
\hline & Mean & SD & Mean & SD & Mean & SD & Mean & SD & Mean & SD & Mean & SD \\
\hline \multicolumn{13}{|l|}{ A. Exogenous variables } \\
\hline Female gender & 0.495 & - & 0.506 & - & 0.331 & - & 0.317 & - & 0.485 & - & 0.211 & - \\
\hline Migration background & 0.062 & - & 0.057 & - & 0.142 & - & 0.071 & - & 0.247 & - & 0.128 & - \\
\hline Number of siblings & 1.642 & 1.403 & 1.606 & 1.351 & 2.208 & 1.966 & 1.706 & 1.345 & 2.763 & 2.482 & 2.294 & 1.921 \\
\hline Mother's education after primary education (years) & 5.441 & 3.209 & 5.585 & 3.164 & 3.181 & 3.058 & 3.508 & 2.950 & 2.742 & 3.046 & 3.193 & 3.170 \\
\hline Father's education after primary education (years) & 5.869 & 3.472 & 6.016 & 3.442 & 3.563 & 3.103 & 3.659 & 2.860 & 3.134 & 3.319 & 3.835 & 3.164 \\
\hline Day of birth within calendar year & 180.316 & 103.336 & 180.358 & 103.334 & 179.654 & 103.517 & 165.365 & 104.101 & 207.536 & 105.434 & 171.358 & 97.016 \\
\hline \multicolumn{13}{|l|}{ B. Endogenous variables } \\
\hline \multicolumn{13}{|c|}{ B.1. Educational outcomes before choice related to dual programme } \\
\hline Delay at start PE & 0.017 & - & 0.016 & - & 0.033 & - & 0.032 & - & 0.021 & - & 0.046 & - \\
\hline Delay at start SE & 0.106 & - & 0.096 & - & 0.268 & - & 0.246 & - & 0.278 & - & 0.284 & - \\
\hline \multicolumn{13}{|l|}{ Track choice at start second year of SE } \\
\hline General track & 0.605 & - & 0.634 & - & 0.157 & - & 0.206 & - & 0.124 & - & 0.128 & - \\
\hline Technical or arts track & 0.260 & - & 0.257 & - & 0.307 & - & 0.246 & - & 0.351 & - & 0.339 & - \\
\hline Vocational track & 0.135 & - & 0.109 & - & 0.536 & - & 0.548 & - & 0.526 & - & 0.532 & - \\
\hline \multicolumn{13}{|l|}{ SE experience at end of CFTSBE } \\
\hline No retention and no downgrade & 0.812 & - & 0.820 & - & 0.681 & - & 0.738 & - & 0.670 & - & 0.624 & - \\
\hline Retention and no downgrade & 0.074 & - & 0.069 & - & 0.160 & - & 0.103 & - & 0.175 & - & 0.211 & - \\
\hline No retention and downgrade & 0.104 & - & 0.102 & - & 0.139 & - & 0.127 & - & 0.134 & - & 0.156 & - \\
\hline Retention and downgrade & 0.010 & - & 0.009 & - & 0.021 & - & 0.032 & - & 0.021 & - & 0.009 & - \\
\hline \multicolumn{13}{|l|}{ B.2. Choice related to dual programme } \\
\hline Participation in dual programme & 0.060 & - & 0.000 & - & 1.000 & - & 1.000 & - & 1.000 & - & 1.000 & - \\
\hline Training centre-based dual programme & 0.023 & - & 0.000 & - & 0.377 & - & 1.000 & - & 0.000 & - & 0.000 & - \\
\hline School-based dual programme & 0.037 & - & 0.000 & - & 0.623 & - & 0.000 & - & 1.000 & - & 1.000 & - \\
\hline Apprenticeship during school-based dual programme & 0.020 & - & 0.000 & - & 0.328 & - & 0.000 & - & 0.000 & - & 1.000 & - \\
\hline
\end{tabular}


Table 1. Summary statistics (continued).

B.3. Later educational and labour market outcomes

\section{SE qualification obtained}

TE enrolment

Employed three months after leaving education

Employed one year after leaving education

Employed five years after leaving education

Permanent contract three months after leaving

education

Permanent contract one year after leaving education

Permanent contract five years after leaving education

$\begin{array}{lllll}0.924 & - & 0.942 & - & 0.633 \\ 0.636 & - & 0.677 & - & 0.000 \\ 0.615 & - & 0.613 & - & 0.6 \\ 0.834 & - & 0.842 & - & 0.7 \\ 0.906 & - & 0.920 & - & 0.780 \\ 0.311 & - & 0.305 & - & 0.4 \\ 0.504 & - & 0.505 & - & 0.4 \\ 0.768 & - & 0.780 & - & 0.6\end{array}$

$\begin{array}{lll}0.633 & - & 0.770 \\ 0.000 & - & 0.000 \\ 0.646 & - & 0.795 \\ 0.723 & - & 0.819 \\ 0.780 & - & 0.900 \\ 0.407 & - & 0.569 \\ 0.497 & - & 0.637 \\ 0.643 & - & 0.758\end{array}$

0.770
0.000
0.795
0.819
0.900
0.569
0.637
0.758

$\begin{array}{ll}- & 0.546 \\ - & 0.000 \\ - & 0.495 \\ - & 0.608 \\ - & 0.627 \\ - & 0.258 \\ - & 0.371 \\ - & 0.494\end{array}$

\begin{tabular}{lll}
- & 0.550 & - \\
- & 0.000 & - \\
- & 0.619 & - \\
- & 0.724 & - \\
- & 0.788 & - \\
- & 0.365 & - \\
- & 0.462 & - \\
- & 0.655 & - \\
\hline
\end{tabular}

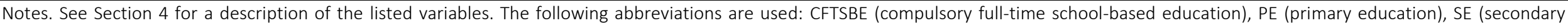
education), and TE (tertiary education). For binary variables no standard deviations are presented. 
Labour market outcome: employed after leaving education

Model

Labour market outcome: permanent contract after leaving education

$\begin{array}{cccc}\begin{array}{c}\text { Dual programme effect } \\ \text { homogeneous by gender }\end{array} & \begin{array}{c}\text { Dual programme effect } \\ \text { heterogeneous by gender }\end{array} & \begin{array}{c}\text { Dual programme effect } \\ \text { homogeneous by gender }\end{array} & \begin{array}{c}\text { Dual programme effect } \\ \text { heterogeneous by gender }\end{array}\end{array}$

(benchmark

\begin{tabular}{|c|c|c|c|c|}
\hline \multicolumn{5}{|l|}{ A. Outcome: SE qualification obtained } \\
\hline Participation in dual programme & $-1.941 * * *(0.729)$ & $-1.996 * * *(0.754)$ & $-2.333 * * *(0.794)$ & $-2.387 * * *(0.837)$ \\
\hline Participation in dual programme $\times$ female gender & & $0.293(0.923)$ & & $0.871(0.971)$ \\
\hline School-based dual programme & $-0.271(0.941)$ & $-0.207(1.028)$ & $-0.045(0.975)$ & $-0.083(1.118)$ \\
\hline Apprenticeship during school-based dual programme & $0.840(1.128)$ & $0.981(1.272)$ & $0.875(1.217)$ & $1.167(1.393)$ \\
\hline \multicolumn{5}{|c|}{ B. Outcome: work status three months after leaving education } \\
\hline Participation in dual programme & $0.930 * * *(0.312)$ & $1.194 * * *(0.343)$ & $1.111^{* * *}(0.261)$ & $1.269 * * *(0.281)$ \\
\hline Participation in dual programme $\times$ female gender & & $-0.641 * *(0.323)$ & & $-0.471(0.347)$ \\
\hline School-based dual programme & $-1.055 * * *(0.389)$ & $-0.995 * *(0.392)$ & $-1.118 * * *(0.383)$ & $-1.082 * * *(0.388)$ \\
\hline Apprenticeship during school-based dual programme & $0.448(0.358)$ & $0.272(0.368)$ & $0.363(0.371)$ & $0.255(0.390)$ \\
\hline \multicolumn{5}{|l|}{ C. Outcome: work status one year after leaving education } \\
\hline Participation in dual programme & $-0.382(0.381)$ & $-0.153(0.430)$ & $-0.048(0.416)$ & $-0.042(0.441)$ \\
\hline Participation in dual programme $\times$ female gender & & $-0.489(0.440)$ & & $-0.010(0.460)$ \\
\hline School-based dual programme & $-0.048(0.439)$ & $0.023(0.452)$ & $-0.134(0.518)$ & $-0.120(0.530)$ \\
\hline Apprenticeship during school-based dual programme & $0.335(0.460)$ & $0.222(0.492)$ & $0.045(0.532)$ & $0.055(0.556)$ \\
\hline \multicolumn{5}{|l|}{ D. Outcome: work status five years after leaving education } \\
\hline Participation in dual programme & $0.174(0.471)$ & $0.387(0.537)$ & $-0.370(0.303)$ & $-0.233(0.346)$ \\
\hline Participation in dual programme $\times$ female gender & & $-0.393(0.438)$ & & $-0.311(0.359)$ \\
\hline School-based dual programme & $-0.939 *(0.528)$ & $-0.941 *(0.530)$ & $-0.586(0.431)$ & $-0.566(0.432)$ \\
\hline Apprenticeship during school-based dual programme & $0.608(0.502)$ & $0.522(0.506)$ & $0.447(0.431)$ & $0.360(0.438)$ \\
\hline $\mathrm{N}$ & 5,541 & 5,541 & 5,541 & 5,541 \\
\hline \# heterogeneity types (K) & 6 & $6^{a}$ & 6 & 6 \\
\hline \# parameters & 239 & 243 & 239 & 243 \\
\hline Log-likelihood & $-19,441.101$ & $-19,436.983$ & $-20,562.977$ & $-20,561.153$ \\
\hline Akaike Information Criterion (AIC) & $39,360.203$ & $39,359.965$ & $41,603.953$ & $41,608.305$ \\
\hline
\end{tabular}

Notes. The presented statistics are estimated coefficients and standard errors between parentheses. ${ }^{*}(* *)\left(\left(^{* *}\right)\right)$ indicates significance at the $10 \%(5 \%)((1 \%))$ significance level. The following abbreviation is used: SE (secondary education).

a The AIC is slightly lower for the model with seven heterogeneity types, i.e. AIC=39,358.177. However, for consistency, we used the model with six heterogeneity types throughout al our analyses. Using a model with seven heterogeneity types for this specification does not substantially change our results. 
Table 3. ATEs on educational and labour market outcomes: participation in a dual programme versus full-time school-based education.

\begin{tabular}{|c|c|c|c|}
\hline & $\begin{array}{c}\text { (1) } \\
\text { Total effect }\end{array}$ & $\begin{array}{c}\text { (2) } \\
\text { Direct effect }\end{array}$ & $\begin{array}{c}\text { (3) } \\
\text { Indirect effect }\end{array}$ \\
\hline \multicolumn{4}{|l|}{ A. Treatment: training centre-based dual programme } \\
\hline SE qualification obtained & $0.945 * * *[0.893,0.989]$ & & \\
\hline Employed three months after leaving education & $1.297^{* * *}[1.117,1.449]$ & $1.306 * * *[1.129,1.456]$ & $-0.009 * *[-0.021,-0.001]$ \\
\hline Employed one year after leaving education & {$[0.914,1.093]$} & {$[0.826,1.044]$} & $0.068^{* * *}[0.118,0.019]$ \\
\hline Employed five years after leaving education & {$[0.943,1.051]$} & {$[0.943,1.050]$} & {$[0.014,0.010]$} \\
\hline \multicolumn{4}{|c|}{ B. Treatment: school-based dual programme with apprenticeship } \\
\hline SE qualification obtained & {$[0.891,1.009]$} & & \\
\hline Employed three months after leaving education & {$[0.872,1.344]$} & {$[0.885,1.349]$} & {$[-0.024,0.003]$} \\
\hline Employed one year after leaving education & {$[0.859,1.111]$} & {$[0.847,1.084]$} & {$[-0.031,0.071]$} \\
\hline Employed five years after leaving education & {$[0.884,1.047]$} & {$[0.890,1.044]$} & {$[-0.019,0.016]$} \\
\hline
\end{tabular}

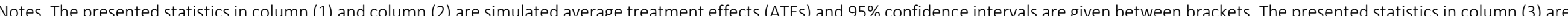

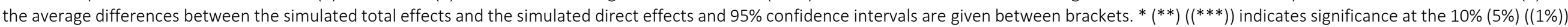

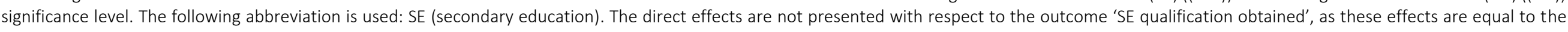
total effects. Similarly, the indirect effects are not presented with respect to the outcome 'SE qualification obtained', as these effects are zero. 
Table 4. ATEs on labour market outcomes: participation in a dual programme versus full-time school-based education.

Employed

Total effect

A. Treatment: training centre-based dual programme

Work status three months after leaving education

Work status one year after leaving education

$\begin{array}{ll}1.297^{* * *} & {[1.117,1.449]} \\ 1.011 & {[0.914,1.093]} \\ 1.009 & {[0.943,1.051]}\end{array}$

Permanent contract

Work status five years after leaving education

1.009

$[0.943,1.051]$

$1.789 * * *[1.383,2.216]$

B. Treatment: school-based dual programme with apprenticeship

Work status three months after leaving education

1.129

$[0.872,1.344]$

1.003

$[0.859,1.111]$

Work status one year after leaving education

0.985

[0.884, 1.047]

$1.267 * * \quad[1.038,1.482]$

$0.979 \quad[0.847,1.090]$

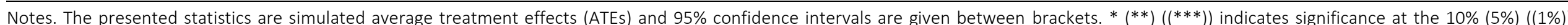
significance level. The effects are not presented with respect to the outcome 'SE qualification obtained', as these effects are equal to the total effects in the previous table. 
Table 5. ATEs on educational and labour market outcomes: direct comparison of dual programmes.

\begin{tabular}{lc}
\hline \hline & $\begin{array}{c}\text { Training centre-based dual programme } \\
\text { versus school-based dual programme }\end{array}$ \\
\hline Secondary education qualification obtained & $0.982[0.915,1.093]$ \\
Employed three months after leaving education & $1.165[0.960,1.427]$ \\
Employed one year after leaving education & $1.013[0.901,1.157]$ \\
Employed five years after leaving education & $1.025[0.945,1.132]$ \\
\hline \hline
\end{tabular}

Notes. The presented statistics are simulated average treatment effects (ATEs) and 95\% confidence intervals are given between brackets. $\left.*^{* *}\right)((* * *))$ indicates significance at the $10 \%(5 \%)((1 \%))$ significance level. The following abbreviation is used: SE (secondary education). 
30

25

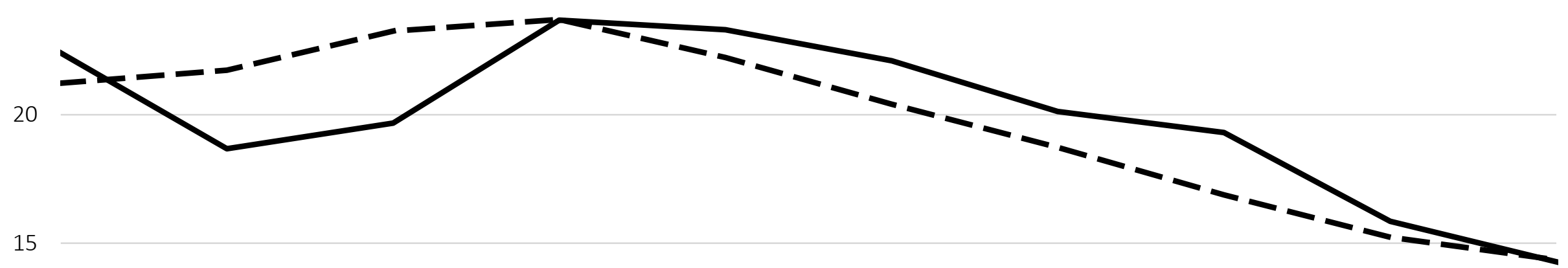

10

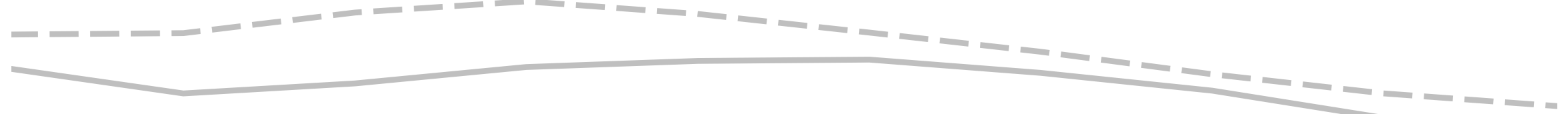

5

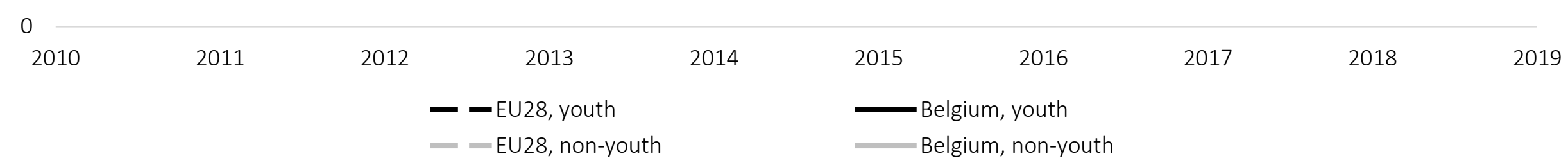

Notes. Source: Eurostat. Youth: between 15 and 24 years old; non-youth: between 25 and 74 years old. 
Figure 2. Youth unemployment rates in the EU28 and Belgium by highest obtained education level.

45

40

35

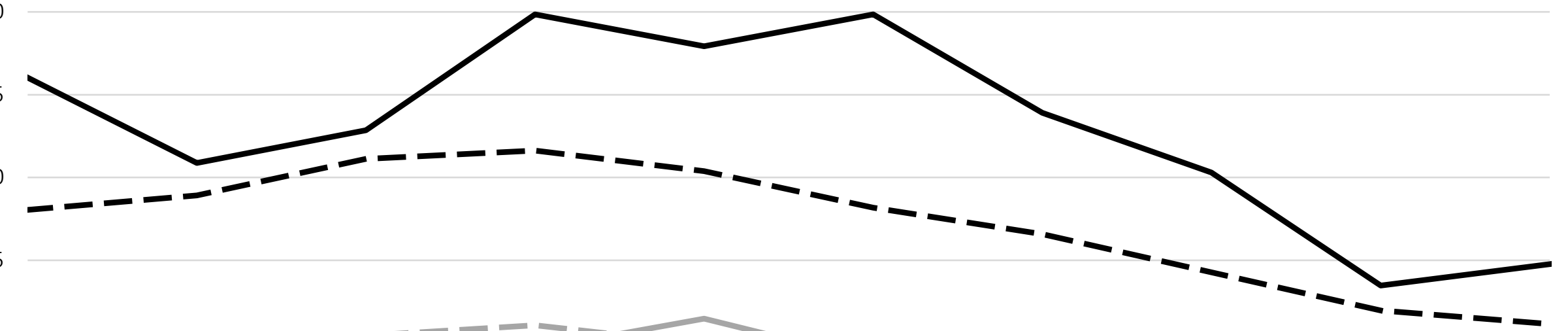

20

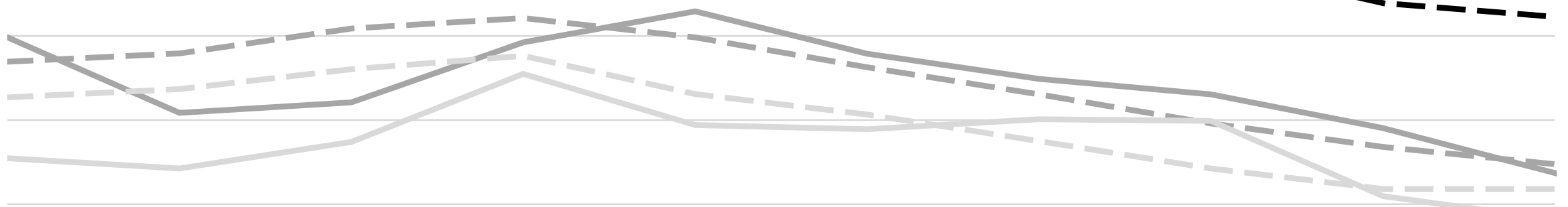

10

5

0 2010 2011

- EU28, below upper secondary - EU28, upper secondary, non-tertiary - EU28, tertiary
Belgium, below upper secondary

Belgium, upper secondary, non-tertiary

_. Belgium, tertiary

Notes. Source: Eurostat. Youth: between 15 and 24 years old. 
Figure 3. Organisation of education in Flanders.

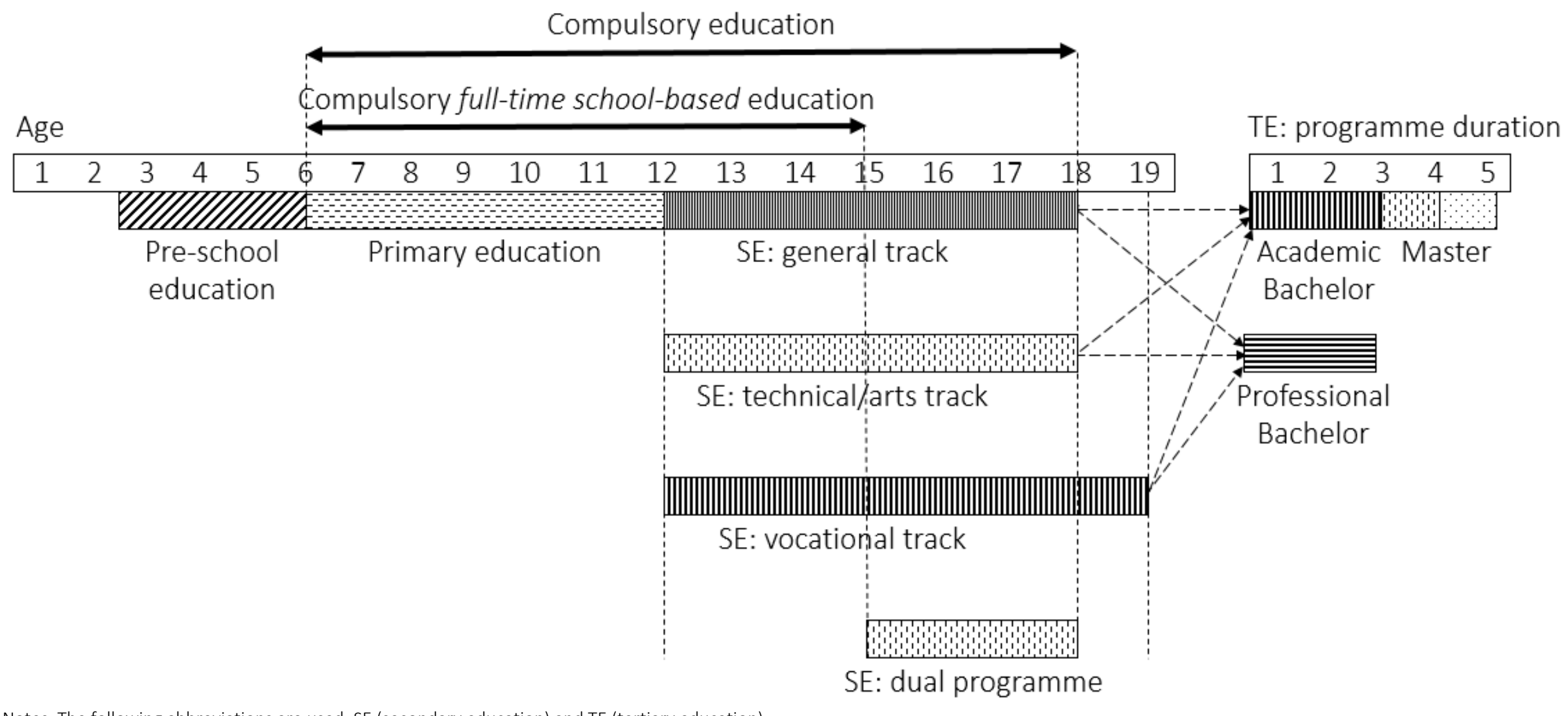

Notes. The following abbreviations are used: SE (secondary education) and TE (tertiary education). 
Figure 4. Schematic overview of the econometric model.

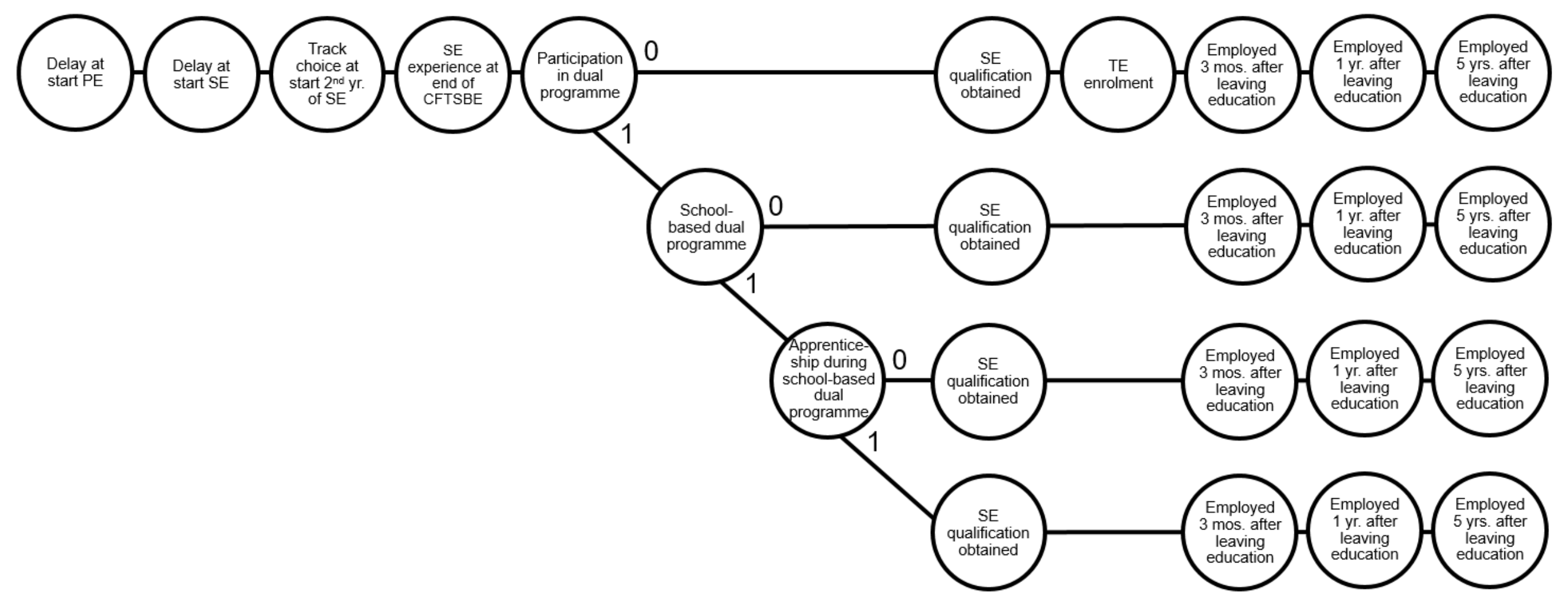

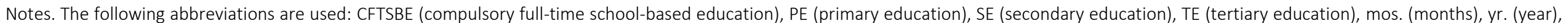
and yrs. (years). 
Figure 5. Goodness of fit for the simulated probabilities.
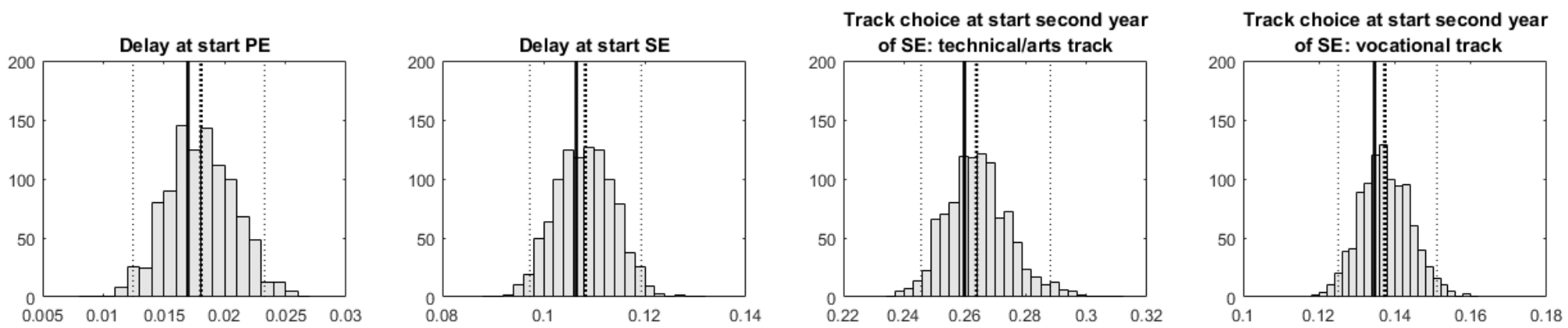

SE experience at end of CFTSBE:

\section{SE experience at end of CFTSB} not delayed, downgraded

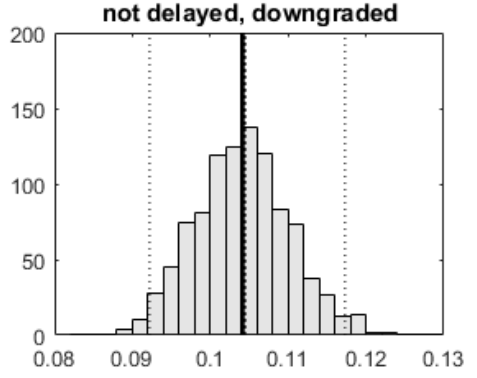

\section{SE experience at end of CFTSBE:} delayed and downgraded
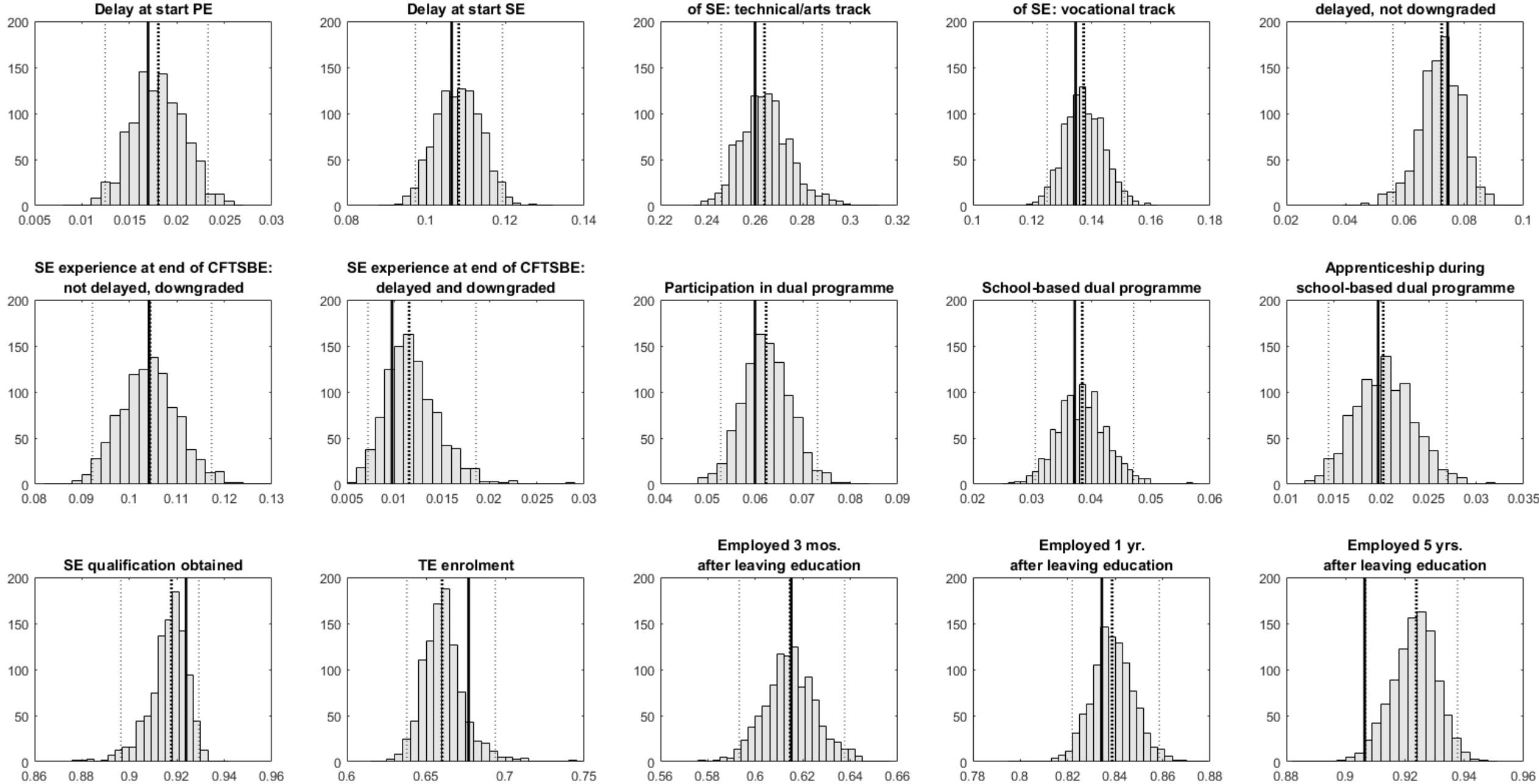

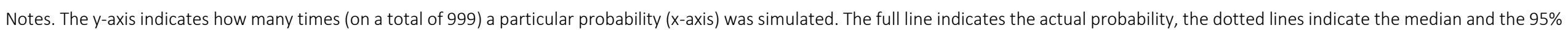

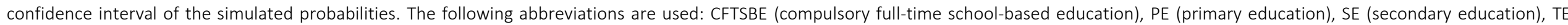
(tertiary education), mos. (months), yr. (year), and yrs. (years). 
Table A-1. Benchmark model: model selection.

\begin{tabular}{cccc}
\hline \hline$(1)$ & $(2)$ & $(3)$ & $(4)$ \\
\# heterogeneity types $(K)$ & \# parameters & Log-likelihood & Akaike Information Criterion \\
\hline 1 & 212 & $-19,602.013$ & $39,628.027$ \\
2 & 231 & $-19,501.459$ & $39,464.917$ \\
3 & 233 & $-19,455.369$ & $39,376.737$ \\
4 & 235 & $-19,452.384$ & $39,374.768$ \\
5 & 237 & $-19,447.588$ & $39,369.175$ \\
6 & 239 & $-19,441.101$ & $39,360.203$ \\
7 & 241 & $-19,439.929$ & $39,361.859$ \\
8 & 243 & $-19,439.051$ & $39,364.103$ \\
\hline \hline
\end{tabular}


Table A-2. Benchmark model: full estimation results.

\begin{tabular}{|c|c|c|}
\hline & Coefficien & nt (SE) \\
\hline \multicolumn{3}{|c|}{ A. Outcome: Delay at start primary education } \\
\hline Female gender & -0.048 & $(0.243)$ \\
\hline Migration background & $1.281 * * *$ & $(0.390)$ \\
\hline Number of siblings & 0.019 & $(0.089)$ \\
\hline Mother's education after PE (years) & -0.031 & $(0.050)$ \\
\hline Father's education after PE (years) & 0.032 & $(0.046)$ \\
\hline Day of birth within calendar year & $0.005^{* * *}$ & $(0.001)$ \\
\hline Unemployment rate & 0.017 & $(0.056)$ \\
\hline Intercept & $-5.854^{* * *}$ & $(0.990)$ \\
\hline \multicolumn{3}{|l|}{ B. Outcome: Delay at start SE } \\
\hline Female gender & $-0.285^{* * *}$ & (0.099) \\
\hline Migration background & $0.525^{* * *}$ & $(0.162)$ \\
\hline Number of siblings & $0.096 * * *$ & $(0.032)$ \\
\hline Mother's education after PE (years) & $-0.139 * * *$ & $(0.019)$ \\
\hline Father's education after PE (years) & $-0.081^{* * *}$ & $(0.018)$ \\
\hline Day of birth within calendar year & $0.003^{* * *}$ & $(0.000)$ \\
\hline Unemployment rate & 0.011 & $(0.017)$ \\
\hline Delay at start primary education & $3.473^{* * *}$ & $(0.283)$ \\
\hline Intercept & $-1.828 * * *$ & $(0.292)$ \\
\hline \multicolumn{3}{|c|}{ C. Outcome: Track choice at start second year of SE: technical or arts track } \\
\hline Female gender & $-0.628 * * *$ & $(0.089)$ \\
\hline Migration background & $-0.352 *$ & $(0.195)$ \\
\hline Number of siblings & $0.080 * *$ & $(0.035)$ \\
\hline Mother's education after PE (years) & $-0.194^{* * *}$ & $(0,020)$ \\
\hline Father's education after PE (years) & $-0.187^{* * *}$ & $(0.018)$ \\
\hline Day of birth within calendar year & $0.001 * * *$ & $(0.000)$ \\
\hline Unemployment rate & $0.043 * * *$ & $(0.014)$ \\
\hline Delay at start primary education & -0.252 & $(0.365)$ \\
\hline Delay at start secondary education & $1.857^{* * *}$ & $(0.202)$ \\
\hline Intercept & $1.603 * * *$ & $(0.321)$ \\
\hline \multicolumn{3}{|c|}{ D. Outcome: Track choice at start second year of SE: vocational track } \\
\hline Female gender & $-0.704^{* * *}$ & $(0.138)$ \\
\hline Migration background & -0.375 & $(0.269)$ \\
\hline Number of siblings & $0.238 * * *$ & $(0.048)$ \\
\hline Mother's education after PE (years) & $-0.355^{* * *}$ & $(0.031)$ \\
\hline Father's education after PE (years) & $-0.295^{* * *}$ & $(0.028)$ \\
\hline Day of birth within calendar year & $0.002 * * *$ & $(0.001)$ \\
\hline Unemployment rate & $0.096 * * *$ & $(0.021)$ \\
\hline Delay at start primary education & -0.176 & $(0.555)$ \\
\hline Delay at start secondary education & $3.252 * * *$ & $(0.263)$ \\
\hline Intercept & $1.071^{* *}$ & $(0.446)$ \\
\hline \multicolumn{3}{|c|}{ E. Outcome: SE experience at end of CFTSBE: delayed, not downgraded } \\
\hline Female gender & $-0.434^{* * *}$ & $(0.135)$ \\
\hline Migration background & $0.493^{* *}$ & $(0.240)$ \\
\hline Number of siblings & 0.055 & $(0.043)$ \\
\hline Mother's education after PE (years) & 0.009 & $(0.027)$ \\
\hline Father's education after PE (years) & $0.061 * * *$ & $(0.024)$ \\
\hline
\end{tabular}


Table A-2. Benchmark model: full estimation results (continued).

\begin{tabular}{|c|c|c|}
\hline \multirow[b]{2}{*}{ Day of birth within calendar year } & \multicolumn{2}{|c|}{ Coefficient (SE) } \\
\hline & 0.000 & $(0.001)$ \\
\hline Unemployment rate & -0.012 & $(0.022)$ \\
\hline Delay at start primary education & -0.624 & $(0.638)$ \\
\hline Delay at start secondary education & $-1.113^{* * *}$ & $(0.238)$ \\
\hline Track choice at start second year of SE: technical or arts track & $2.973^{* * *}$ & $(0.383)$ \\
\hline Track choice at start second year of SE: vocational track & $3.691 * * *$ & $(0.530)$ \\
\hline Intercept & $-6.115^{* * *}$ & $(0.652)$ \\
\hline \multicolumn{3}{|c|}{ F. Outcome: SE experience at end of CFTSBE: not delayed, downgraded } \\
\hline Female gender & -0.113 & $(0.094)$ \\
\hline Migration background & -0.365 & $(0.251)$ \\
\hline Number of siblings & 0.021 & $(0.038)$ \\
\hline Mother's education after PE (years) & $-0.095 * * *$ & $(0.020)$ \\
\hline Father's education after PE (years) & $-0.078 * * *$ & $(0.019)$ \\
\hline Day of birth within calendar year & 0.000 & $(0.000)$ \\
\hline Unemployment rate & $0.027^{*}$ & $(0.015)$ \\
\hline Delay at start primary education & -1.309 & $(1.143)$ \\
\hline Delay at start secondary education & $-4.053 * * *$ & $(1.124)$ \\
\hline Track choice at start second year of SE: technical or arts track & -0.155 & $(0.169)$ \\
\hline Track choice at start second year of SE: vocational track & $-50^{a}$ & \\
\hline Intercept & $-1.333^{* * *}$ & $(0.352)$ \\
\hline \multicolumn{3}{|c|}{ G. Outcome: SE experience at end of CFTSBE: delayed and downgraded } \\
\hline Female gender & -0.414 & $(0.347)$ \\
\hline Migration background & -0.454 & $(0.884)$ \\
\hline Number of siblings & 0.094 & $(0.122)$ \\
\hline Mother's education after PE (years) & -0.052 & $(0.066)$ \\
\hline Father's education after PE (years) & $-0.158 * * *$ & $(0.059)$ \\
\hline Day of birth within calendar year & -0.001 & $(0.002)$ \\
\hline Unemployment rate & 0.015 & $(0.054)$ \\
\hline Delay at start primary education & 0.345 & $(1.821)$ \\
\hline Delay at start secondary education & -0.388 & $(1.162)$ \\
\hline Track choice at start second year of SE: technical or arts track & $-1.206^{*}$ & $(0.710)$ \\
\hline Track choice at start second year of SE: vocational track & $-50^{a}$ & \\
\hline Intercept & $-2.785 * * *$ & $(1.030)$ \\
\hline \multicolumn{3}{|l|}{ H. Outcome: Participation in dual programme } \\
\hline Female gender & $-0.716^{* * *}$ & $(0.148)$ \\
\hline Migration background & 0.058 & $(0.231)$ \\
\hline Number of siblings & 0.071 & $(0.043)$ \\
\hline Mother's education after PE (years) & -0.039 & $(0.029)$ \\
\hline Father's education after PE (years) & -0.031 & $(0.027)$ \\
\hline Day of birth within calendar year & -0.001 & $(0.001)$ \\
\hline Unemployment rate & $-0.110 * * *$ & $(0.023)$ \\
\hline Delay at start primary education & 0.258 & $(0.482)$ \\
\hline Delay at start secondary education & 0.026 & $(0.185)$ \\
\hline Track choice at start second year of SE: technical or arts track & $2.244^{* * *}$ & $(0.373)$ \\
\hline Track choice at start second year of SE: vocational track & $4.304^{* * *}$ & $(0.526)$ \\
\hline SE experience at end of CFTSBE: delayed, not downgraded & 0.157 & $(0.274)$ \\
\hline SE experience at end of CFTSBE: not delayed, downgraded & $1.416^{* * *}$ & $(0.236)$ \\
\hline
\end{tabular}


Table A-2. Benchmark model: full estimation results (continued).

\begin{tabular}{|c|c|c|}
\hline & \multicolumn{2}{|c|}{ Coefficient (SE) } \\
\hline SE experience at end of CFTSBE: delayed and downgraded & $2.270^{* * *}$ & $(0.560)$ \\
\hline Intercept & $-3.665^{* * *}$ & $(0.617)$ \\
\hline \multicolumn{3}{|l|}{ I. Outcome: School-based dual programme } \\
\hline Female gender & -0.115 & $(0.320)$ \\
\hline Migration background & 0.828 & $(0.552)$ \\
\hline Number of siblings & $0.221 * *$ & $(0.108)$ \\
\hline Mother's education after PE (years) & -0.007 & $(0.058)$ \\
\hline Father's education after PE (years) & 0.044 & $(0.058)$ \\
\hline Day of birth within calendar year & $0.002^{*}$ & $(0.001)$ \\
\hline Unemployment rate & -0.006 & $(0.044)$ \\
\hline Delay at start primary education & 0.051 & $(0.903)$ \\
\hline Delay at start secondary education & -0.207 & $(0.374)$ \\
\hline Track choice at start second year of SE: technical or arts track & $2.560 * * *$ & $(0.890)$ \\
\hline Track choice at start second year of SE: vocational track & $2.859 * *$ & $(1.120)$ \\
\hline SE experience at end of CFTSBE: delayed, not downgraded & 0.112 & $(0.555)$ \\
\hline SE experience at end of CFTSBE: not delayed, downgraded & 0.518 & $(0.531)$ \\
\hline SE experience at end of CFTSBE: delayed and downgraded & 0.410 & $(1.705)$ \\
\hline Intercept & $-3.750 * * *$ & $(1.323)$ \\
\hline \multicolumn{3}{|l|}{ J. Outcome: Apprenticeship during school-based dual programme } \\
\hline Female gender & $-1.179 * * *$ & $(0.392)$ \\
\hline Migration background & -0.460 & $(0.519)$ \\
\hline Number of siblings & -0.021 & $(0.097)$ \\
\hline Mother's education after PE (years) & 0.002 & $(0.074)$ \\
\hline Father's education after PE (years) & 0.029 & $(0.064)$ \\
\hline Day of birth within calendar year & $-0.003^{*}$ & $(0.002)$ \\
\hline Unemployment rate & -0.009 & $(0.057)$ \\
\hline Delay at start primary education & 0.902 & $(1.214)$ \\
\hline Delay at start secondary education & 0.199 & $(0.458)$ \\
\hline Track choice at start second year of SE: technical or arts track & 0.091 & $(0.961)$ \\
\hline Track choice at start second year of SE: vocational track & 0.607 & $(1.260)$ \\
\hline SE experience at end of CFTSBE: delayed, not downgraded & 0.235 & $(0.595)$ \\
\hline SE experience at end of CFTSBE: not delayed, downgraded & 0.557 & $(0.596)$ \\
\hline SE experience at end of CFTSBE: delayed and downgraded & -0.887 & $(2.210)$ \\
\hline Intercept & 0.602 & $(1.592)$ \\
\hline
\end{tabular}

\section{K. Outcome: SE qualification obtained}

Female gender

Migration background

$-2.279 * * *(0.597)$

Number of siblings

$-0.075 \quad(0.092)$

Mother's education after PE (years)

$-0.163 * * \quad(0.068)$

Father's education after PE (years)

$-0.007 \quad(0.055)$

Day of birth within calendar year

$0.005 * * *(0.002)$

Unemployment rate

$0.150 * * \quad(0.064)$

Delay at start primary education

$0.080 \quad(1.475)$

Delay at start secondary education

$0.430 \quad(0.561)$

Track choice at start second year of SE: technical or arts track

$-12.245 * * *(2.479)$

Track choice at start second year of SE: vocational track

$-20.440 * * *(3.995)$

SE experience at end of CFTSBE: delayed, not downgraded

$2.786 * * *(0.984)$ 
Table A-2. Benchmark model: full estimation results (continued).

\begin{tabular}{|c|c|c|}
\hline \multirow[b]{2}{*}{ SE experience at end of CFTSBE: not delayed, downgraded } & \multicolumn{2}{|c|}{ Coefficient (SE) } \\
\hline & -1.047 & $(0.805)$ \\
\hline SE experience at end of CFTSBE: delayed and downgraded & $-6.914^{*}$ & $(3.661)$ \\
\hline Participation in dual programme & $-1.941 * * *$ & $(0.729)$ \\
\hline School-based dual programme & -0.271 & $(0.941)$ \\
\hline Apprenticeship during school-based dual programme & 0.840 & $(1.128)$ \\
\hline Intercept & $21.674 * * *$ & $(4.035)$ \\
\hline \multicolumn{3}{|l|}{ L. Outcome: TE enrolment } \\
\hline Female gender & $1.304^{* * *}$ & $(0.328)$ \\
\hline Migration background & -0.636 & $(0.528)$ \\
\hline Number of siblings & 0.152 & $(0.101)$ \\
\hline Mother's education after PE (years) & -0.056 & $(0.052)$ \\
\hline Father's education after PE (years) & $0.132 * * *$ & $(0.050)$ \\
\hline Day of birth within calendar year & $0.006^{* * *}$ & $(0.002)$ \\
\hline Unemployment rate & $0.461 * * *$ & $(0.079)$ \\
\hline Delay at start primary education & $3.195^{* * *}$ & $(1.003)$ \\
\hline Delay at start secondary education & -0.031 & $(0.524)$ \\
\hline Track choice at start second year of SE: technical or arts track & $-12.044^{* * *}$ & $(1.730)$ \\
\hline Track choice at start second year of SE: vocational track & $-18.462^{* * *}$ & $(2.537)$ \\
\hline SE experience at end of CFTSBE: delayed, not downgraded & $3.666^{* * *}$ & $(0.737)$ \\
\hline SE experience at end of CFTSBE: not delayed, downgraded & $-4.901 * * *$ & $(0.750)$ \\
\hline SE experience at end of CFTSBE: delayed and downgraded & $-8.170 * * *$ & $(2.179)$ \\
\hline Intercept & $7.716^{* * *}$ & $(1.319)$ \\
\hline \multicolumn{3}{|l|}{ M. Outcome: Employed three months after leaving education } \\
\hline Female gender & $-0.225 * * *$ & $(0.061)$ \\
\hline Migration background & $-0.744 * * *$ & $(0.140)$ \\
\hline Number of siblings & $-0.048 * *$ & $(0.023)$ \\
\hline Mother's education after PE (years) & -0.008 & $(0.013)$ \\
\hline Father's education after PE (years) & $-0.026 * *$ & $(0.011)$ \\
\hline Day of birth within calendar year & 0.000 & $(0.000)$ \\
\hline Unemployment rate & $-0.105^{* * *}$ & $(0.015)$ \\
\hline Delay at start primary education & -0.196 & $(0.264)$ \\
\hline Delay at start secondary education & -0.061 & $(0.114)$ \\
\hline Track choice at start second year of SE: technical or arts track & 0.073 & $(0.195)$ \\
\hline Track choice at start second year of SE: vocational track & 0.069 & $(0.344)$ \\
\hline SE experience at end of CFTSBE: delayed, not downgraded & -0.077 & $(0.151)$ \\
\hline SE experience at end of CFTSBE: not delayed, downgraded & 0.147 & $(0.110)$ \\
\hline SE experience at end of CFTSBE: delayed and downgraded & 0.205 & $(0.355)$ \\
\hline Participation in dual programme & $0.930 * * *$ & $(0.312)$ \\
\hline School-based dual programme & $-1.055^{* * *}$ & $(0.389)$ \\
\hline Apprenticeship during school-based dual programme & 0.448 & $(0.358)$ \\
\hline SE qualification obtained & $0.577^{* * *}$ & $(0.178)$ \\
\hline TE enrolment & -0.175 & $(0.174)$ \\
\hline Intercept & $1.436 * * *$ & $(0.458)$ \\
\hline \multicolumn{3}{|l|}{ N. Outcome: Employed one year after leaving education } \\
\hline Female gender & $-0.379 * * *$ & $(0.098)$ \\
\hline Migration background & $-0.570 * * *$ & $(0.196)$ \\
\hline Number of siblings & $-0.060^{*}$ & $(0.032)$ \\
\hline
\end{tabular}


Table A-2. Benchmark model: full estimation results (continued).

\begin{tabular}{lcc}
\hline \hline & Coefficient (SE) \\
\hline Mother's education after PE (years) & -0.024 & $(0.020)$ \\
Father's education after PE (years) & -0.017 & $(0.018)$ \\
Day of birth within calendar year & $-0.001^{*}$ & $(0.000)$ \\
Unemployment rate & $-0.111^{* * *}(0.021)$ \\
Delay at start primary education & -0.549 & $(0.376)$ \\
Delay at start secondary education & 0.075 & $(0.160)$ \\
Track choice at start second year of SE: technical or arts track & $-0.910^{* * *}(0.353)$ \\
Track choice at start second year of SE: vocational track & $-1.657^{* * *}(0.605)$ \\
SE experience at end of CFTSBE: delayed, not downgraded & 0.382 & $(0.231)$ \\
SE experience at end of CFTSBE: not delayed, downgraded & -0.263 & $(0.184)$ \\
SE experience at end of CFTSBE: delayed and downgraded & -0.791 & $(0.568)$ \\
Participation in dual programme & -0.382 & $(0.381)$ \\
School-based dual programme & -0.048 & $(0.439)$ \\
Apprenticeship during school-based dual programme & 0.335 & $(0.460)$ \\
SE qualification obtained & 0.338 & $(0.258)$ \\
TE enrolment & -0.178 & $(0.284)$ \\
Employed three months after leaving education & $2.319^{* * *}(0.109)$ \\
Intercept & $3.226^{* * *}(0.778)$
\end{tabular}

O. Outcome: Employed five years after leaving education

Female gender

$-0.669 * * *(0.168)$

Migration background

$-0.618 * * \quad(0.271)$

Number of siblings

$-0.138 * * *(0.041)$

Mother's education after PE (years)

$0.021 \quad(0.033)$

Father's education after PE (years)

$-0.007 \quad(0.030)$

Day of birth within calendar year

$0.001 \quad(0.001)$

Unemployment rate

$-0.038 \quad(0.047)$

Delay at start primary education

$0.145 \quad(0.655)$

Delay at start secondary education

$0.010 \quad(0.225)$

Track choice at start second year of SE: technical or arts track

$-0.936 \quad(0.672)$

Track choice at start second year of SE: vocational track

$-2.386^{* *}(1.082)$

SE experience at end of CFTSBE: delayed, not downgraded

$0.339 \quad(0.356)$

SE experience at end of CFTSBE: not delayed, downgraded

$-0.192 \quad(0.304)$

SE experience at end of CFTSBE: delayed and downgraded

$-1.580 * * \quad(0.729)$

Participation in dual programme

$0.174 \quad(0.471)$

School-based dual programme

$-0.939 * \quad(0.528)$

Apprenticeship during school-based dual programme

$0.608 \quad(0.502)$

SE qualification obtained

$0.064 \quad(0.395)$

TE enrolment

$-0.188 \quad(0.501)$

Employed three months after leaving education

$0.153 \quad(0.182)$

Employed one year after leaving education

$1.197 * * *(0.187)$

Intercept

$3.988 * * *$ (1.415)

\begin{tabular}{ll}
\hline P. Unobserved heterogeneity distribution & $-1.899^{* * *}(0.124)$ \\
$q_{2}$ & -0.124 \\
$q_{3}$ & $(0.113)$ \\
$q_{4}$ & $-0.887^{* * *}(0.194)$ \\
$q_{5}$ & $-3.787^{* * *}(0.313)$ \\
$q_{6}$ & $-3.538^{* * *}(0.552)$
\end{tabular}


Table A-2. Benchmark model: full estimation results (continued).

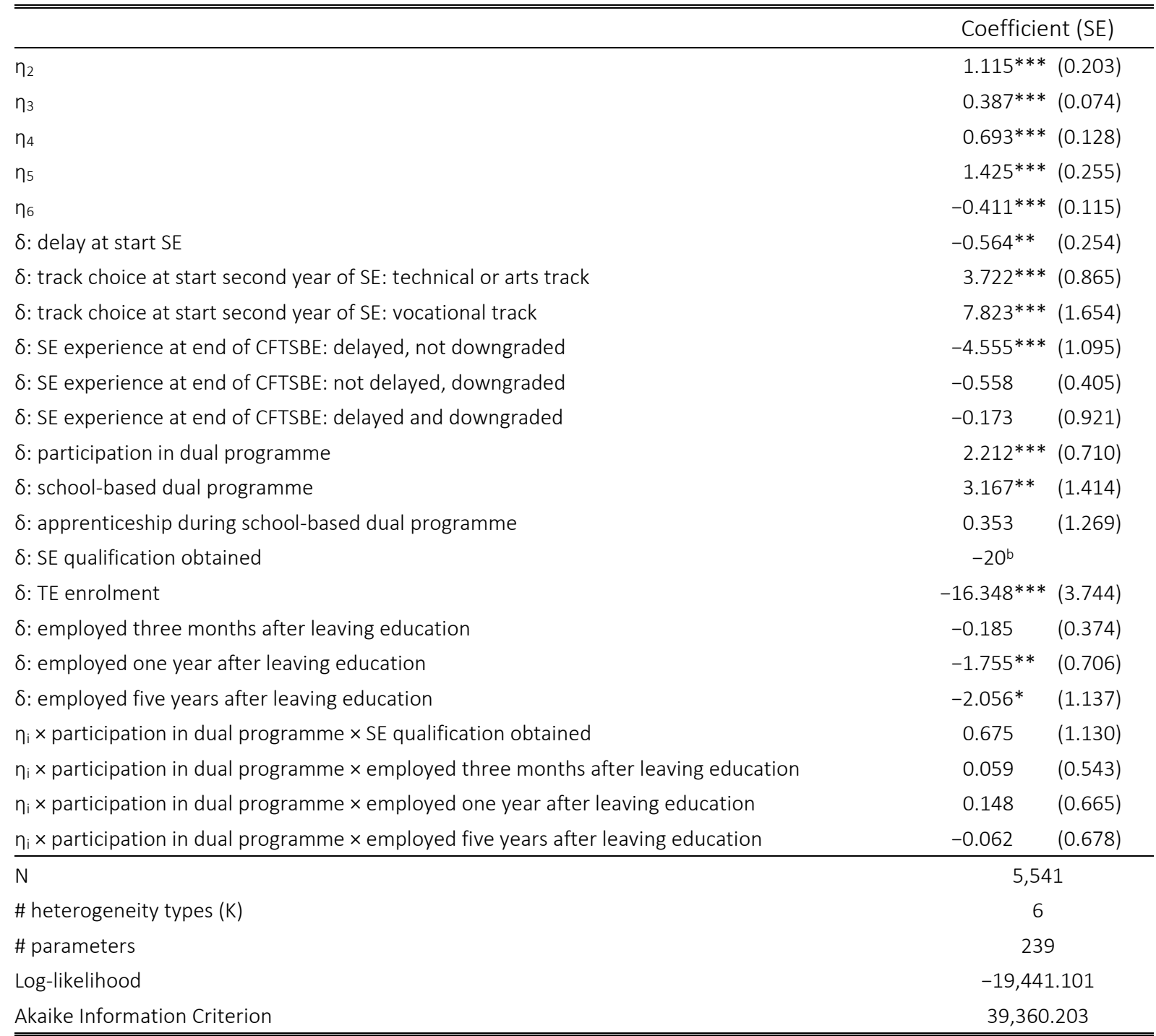

Notes. The presented statistics are estimated coefficients and standard errors between parentheses. ${ }^{*}\left({ }^{* *}\right)\left(\left({ }^{* * *}\right)\right)$ indicates significance at the 10\% (5\%) ((1\%)) significance level. The following abbreviations are used: CFTSBE (compulsory full-time school-based education), PE (primary education), SE (secondary education), and TE (tertiary education).

a As the outcome 'downgraded' is not possible for students in the vocational track (the lowest track), these parameters were estimated with a large negative number $(-50)$, causing a 0 probability with respect to this outcome for students in the vocational track.

${ }^{b}$ One parameter of the unobserved heterogeneity distribution is estimated as a very large negative number causing a 0 or 1 probability with respect to secondary education qualification for some heterogeneity types. This is numerically problematic; therefore, in the spirit of Gaure et al. (2007), we stack it to -20, and kept it out of further estimation. 
Table A-3. Goodness of fit for the simulated probabilities.

\begin{tabular}{lcc}
\hline \hline & $(1)$ & $(2)$ \\
& Actual probability & Simulated probability [95\% Cl] \\
\hline Delay at start PE & 0.017 & $0.018[0.013,0.023]$ \\
Delay at start SE & 0.106 & $0.108[0.097,0.119]$ \\
Track choice at start second year of SE & & 0.598 \\
General track (reference) & 0.605 & $0.264[0.246,0.288]$ \\
Technical or arts track & 0.260 & $0.138[0.125,0.151]$ \\
Vocational track & 0.135 & \\
SE experience at the end of CFTSBE & & 0.812 \\
No retention and no downgrade (reference) & 0.812 & $0.072[0.056,0.085]$ \\
Retention and no downgrade & 0.074 & $0.104[0.092,0.117]$ \\
No retention and downgrade & 0.104 & $0.012[0.007,0.019]$ \\
Retention and downgrade & 0.010 & $0.063[0.053,0.073]$ \\
Participation in dual programme & 0.060 & $0.038[0.031,0.047]$ \\
School-based dual programme & 0.037 & $0.020[0.014,0.027]$ \\
Apprenticeship during school-based dual programme & 0.020 & $0.916[0.896,0.929]$ \\
SE qualification obtained & 0.924 & $0.661[0.638,0.694]$ \\
TE enrolment & 0.636 & $0.615[0.593,0.638]$ \\
Employed three months after leaving education & 0.615 & $0.839[0.822,0.859]$ \\
Employed one year after leaving education & 0.834 & $0.923 * *[0.907,0.938]$ \\
Employed five years after leaving education & 0.906 & \\
\hline \hline
\end{tabular}

Notes. We do not provide confidence intervals for the two reference categories, as these probabilities are not simulated. The probabilities here are calculated by subtracting the simulated probabilities of the non-reference categories from $1 .{ }^{*}$ $\left({ }^{* *}\right)((* *))$ indicates a significant difference between the actual and simulated probabilities at the $10 \%(5 \%)((1 \%))$ significance level. The following abbreviations are used: CFTSBE (compulsory full-time school-based education), PE (primary education), SE (secondary education), and TE (tertiary education). 
Table A-4. ATTs and ATNTs on labour market outcomes: the two dual programmes versus full-time school-based education.

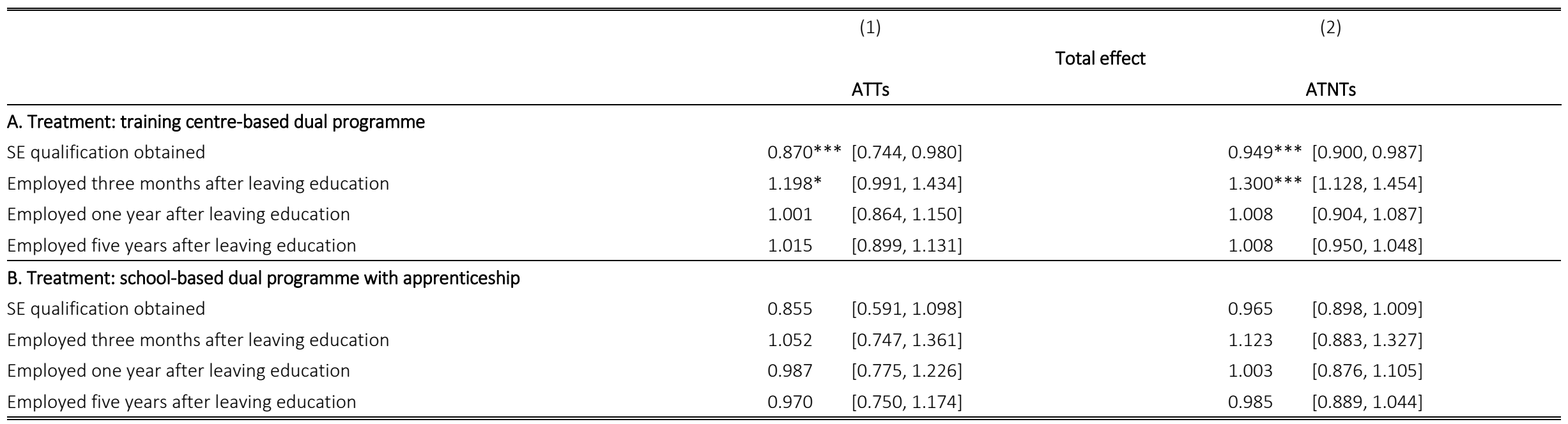

Notes. The presented statistics are simulated average treatment effects on the treated (ATTs) and average treatment effects on the non-treated (ATNTs) and 95\% confidence intervals are given between brackets. ${ }^{*}(*)((* * *))$ indicates significance at the $10 \%(5 \%)((1 \%))$ significance level. The following abbreviation is used: SE (secondary education). 